University of Louisville ThinkIR: The University of Louisville's Institutional Repository

Electronic Theses and Dissertations

$5-2016$

\title{
The electropolishing of electron beam melting, additively manufactured TI6AL4V titanium : relevance, process parameters and surface finish.
}

Austin Lassell

University of Louisville

Follow this and additional works at: https://ir.library.louisville.edu/etd

Part of the Industrial Engineering Commons

\section{Recommended Citation}

Lassell, Austin, "The electropolishing of electron beam melting, additively manufactured TI6AL4V titanium : relevance, process parameters and surface finish." (2016). Electronic Theses and Dissertations. Paper 2369.

https://doi.org/10.18297/etd/2369

This Master's Thesis is brought to you for free and open access by ThinkIR: The University of Louisville's Institutional Repository. It has been accepted for inclusion in Electronic Theses and Dissertations by an authorized administrator of ThinkIR: The University of Louisville's Institutional Repository. This title appears here courtesy of the author, who has retained all other copyrights. For more information, please contact thinkir@louisville.edu. 
THE ELECTROPOLISHING OF ELECTRON BEAM MELTING, ADDITIVELY MANUFACTURED TI6AL4V TITANIUM: RELEVANCE, PROCESS PARAMETERS AND SURFACE FINISH

\title{
By
}

Austin Lassell

B. S. Industrial Engineering, University Of Louisville, 2015

\author{
A Thesis \\ Submitted to the Faculty of the \\ University of Louisville \\ J.B. Speed School of Engineering \\ as Partial Fulfillment of the Requirements \\ for the Professional Degree
}

\section{MASTER OF ENGINEERING}

Program in Industrial Engineering

May 2016 



\section{THE ELECTROPOLISHING OF ELECTRON BEAM MELTING, ADDITIVELY MANUFACTURED Ti-6Al-4V TITANIUM: RELEVANCE, PROCESS PARAMETERS AND SURFACE FINISH}

Submitted by:

Austin Lassell

A Thesis Approved on

\section{(Date)}

By the Following Reading and Examination Committee:

\begin{tabular}{c}
\hline Li Yang, Thesis Director \\
\hline Gail W. Depuy \\
\hline Jacek Jasinski
\end{tabular}




\section{ACKNOWLEDGEMENTS}

I would like to firstly thank Dr. Li Yang as my thesis advisor, prime mentor, and motivator throughout this work. His strong passion and interest in science and engineering as well as his positive spirit are an inspiration to anyone attempting to take on challenging research. Dr. Yang is strongly encouraging no matter the circumstance and only constructive and never critical, a model individual in managing interpersonal relations and high pressure situations. I would also like to thank Hengfeng Gu for his efforts in laying the foundational preliminary research that paved the entry into this work. In addition to my peer Hengfeng, I'd like to reach out in appreciation to undergraduate students Gustavo Paiva and Mohith Buxani for their eager and untiring interest and willingness to volunteer in this work. Within the University of Louisville, Rapid Prototyping Center, I'd like t thank staff members Tim Gornet, Gary Graf, and Joe Vicars for their patient cooperation in assisting with the manufacturing of necessary components.

This work was sponsored by the Intramural Research Initiation Grant at the University of Louisville and the NASA-MSFC grant SC-2019-004. 


\begin{abstract}
Additive Manufacturing (AM) is the next frontier in manufacturing technology, but with this new frontier comes new challenges in post processing techniques. In an attempt to gain further knowledge of the post processing of metal AM components, the Electropolishing (EP) of Electron Beam Melting (EBM), Additively Manufactured Ti6Al-4V alloy parts is investigated in the following work. Additive Manufacturing (AM) is predominant in a number of industries, with electronics and consumer goods, aerospace, automotive and medical constituting the majority of AM sales. For most of these, Powder Bed Fusion (PBF) AM technology is of great interest given the ability of PBF to manufacture using metallic materials. Within metal PBF, there are a number of alloys considered most useful for their existing commonality in industry, good compatibility with metal $\mathrm{PBF}$, and principally performance characteristics, with the most popular of these metals being Ti-6Al-4V. Given that many of the intended applications of Ti-6Al-4V parts require good fatigue performance (such as in engine and structural components) and that surface finish is one of the leading limits to fatigue life, the surface finish improvement of AM Ti-6Al-4V a pressing need. Since AM parts inherently contain difficult, if not impossible to reach, features using traditional methods, EP may be
\end{abstract}


a promising alternative towards improving surface finish. Of the common metal PBF AM technologies, Selective Laser Melting (SLM) and Electron Beam Melting (EBM), the EP of EBM Ti-6Al-4V parts holds the greatest challenge and greatest reward, as EBM Ti$6 \mathrm{Al}-4 \mathrm{~V}$ parts have a rougher surface finish than SLM Ti-6Al-4V parts, but also contain better resultant performance characteristics than SLM Ti-6Al-4V parts. EP is inherently challenging given the wide range of factors concurrently affecting polishing quality, and even more so a challenge when performed on AM parts. AM parts have a rougher initial surface finish and can be more complex than parts that are typically polished using EP. Gaining proper insight into controlling temperature, time, voltage, electrolyte flow, and other factors such that the uncommonly complex and rough AM part surface can be uniformly leveled and polished is a sizeable task that will take years of careful research. However, laying groundwork in this area, through methodical research and experimentation, has provided a number of valuable insights, pointing future research in the right direction. This work has shown that careful focus must be given to the diffusion layer, surface film, the greatest attribute and also challenge of controlling polish quality in EP. If surface EP proves a viable post processing method for EP, then managing many of the factors effecting EP, including time, temperature, voltage, etc., concurrently must be achieved if metal PBF AM components are to be made as equally useable as existing components. 


\section{TABLE OF CONTENTS}

PAGE

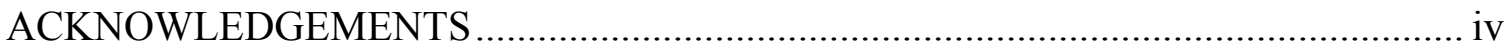

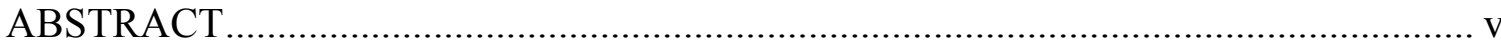

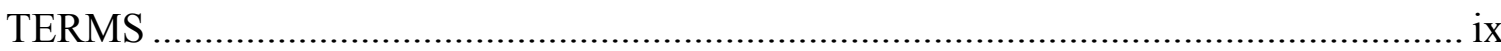

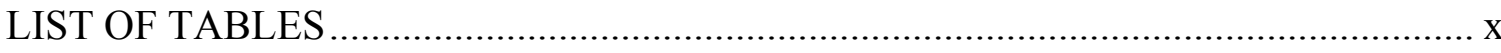

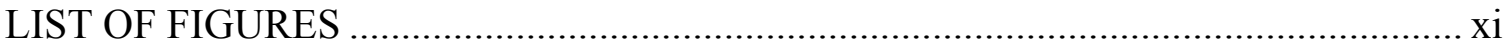

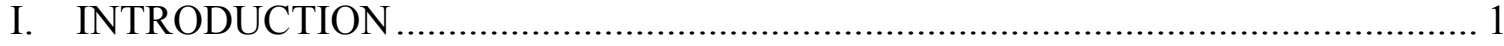

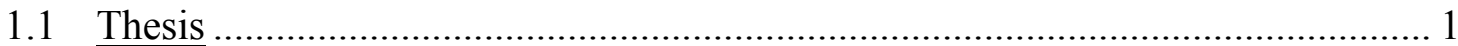

1.2 Brief History of AM ................................................................................. 1

1.3 Powder Bed Fusion AM ............................................................................ 3

1.4 Post Processing Surface Finish in AM ......................................................... 4

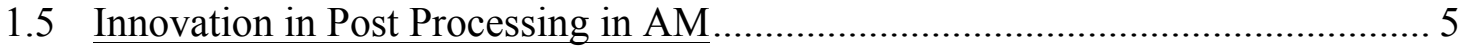

1.6 Focus of Work, Electropolishing of EBM AM ............................................... 6

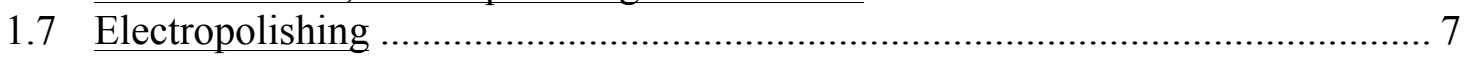

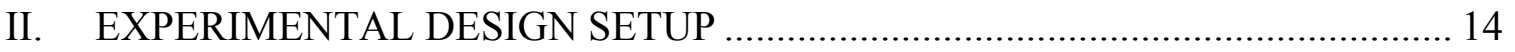

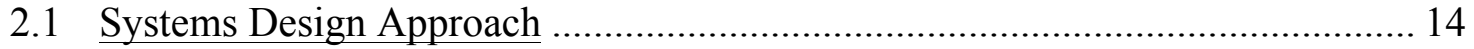

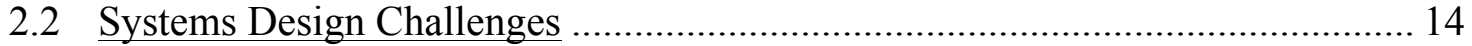

2.3 Design Quality Metrics ............................................................................... 16

2.4 Design Evolution.............................................................................................. 19

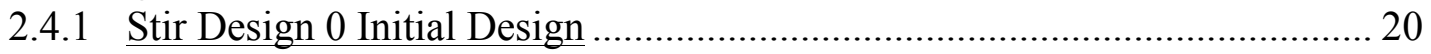

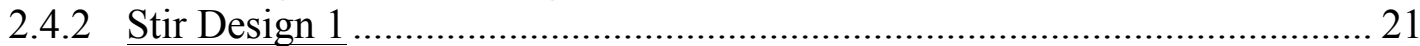

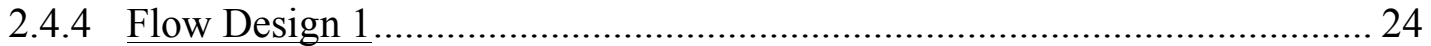

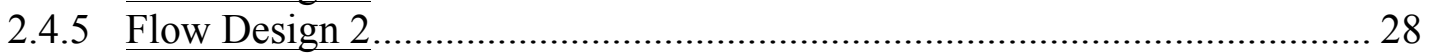

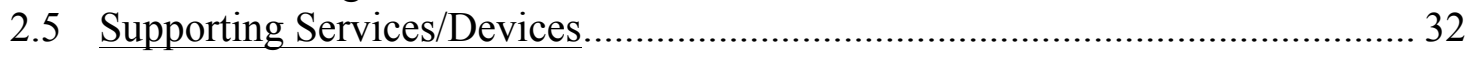

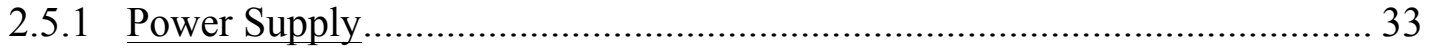

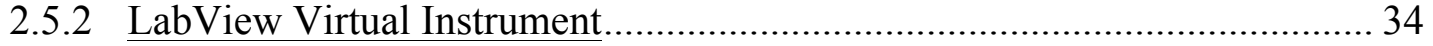

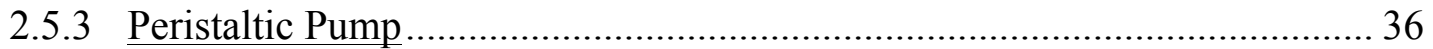

2.5.4 Heating/Cooling Loop Pump....................................................................... 37

2.5.5 Secondary Power Supply ...................................................................... 38

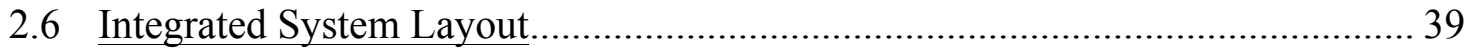

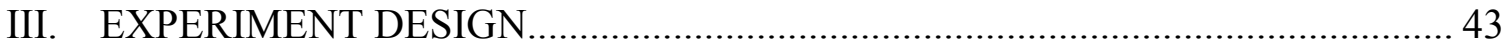

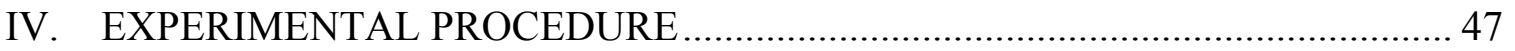

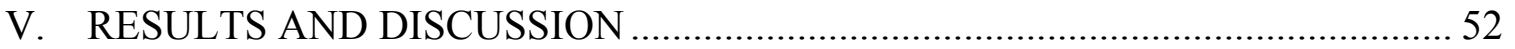

VI. CONCLUSION AND FUTURE WORK .......................................................... 71 


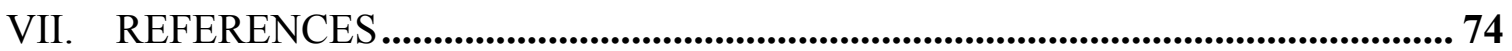




\title{
TERMS
}

\author{
AM - Additive Manufacturing \\ CAD - Computer Aided Design \\ CAM - Computer Aided Manufacturing \\ DAQ - Data Acquisition (module) \\ EBM - Electron Beam Melting \\ EP - Electropolishing \\ $\mathrm{HF}$ - Hydrofluoric Acid \\ PBF - Powder Bed Fusion \\ RP - Rapid Prototyping \\ SLM - Selective Laser Melting \\ FDM - Fused Deposition Modeling \\ VI - Virtual Instrument (commonly, LabView, VI)
}




\section{LIST OF TABLES}

TABLE 1 - Design quality metrics used to ensure resultant system design quality

TABLE 2 - Overview of design evolution in terms of design improvements, design features and iterations.

TABLE 3 - Electrolytic solution calculation for both composition percentages and cost. 


\section{LIST OF FIGURES}

FIGURE 1 - Description of electrolytic cell reaction and main components ....................8

FIGURE 2 - Comparison of electrolytic cell versus galvanic cell.................................8 FIGURE 3 - Progression of electropolishing from (a) initial profile to (b) polishing done during Macrosmoothing and then (c) polishing done during Microsmoothing. Figure from Landolt (Landolt, 1987).

FIGURE 4 - Conceptual drawing of the diffusion layer profile film present during EP. While the hypothetical surface film profile closely follows the sample profile, the resultant surface film profile concentrates less densely at sample profile peaks due to localized hydrodynamic effects (Cleric, Datta, and Landolt, 1984).

FIGURE 5 - Conceptual graph of the current limiting plateau commonly found during EP. At specific potentials, a current limiting plateau exists*. Within the current limiting plateau, a number of potential's exist that may return good polishing. Above the current limiting plateau**, pitting occurs rather than anodic brightening (Hoar, Mears, and

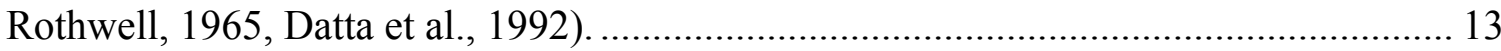

FIGURE 6 - Side view of initial experiment design, Stir Design 0 ................................20

FIGURE 7 - Top view of Stir Design 0 showing anodic sample and cathode support submerged in solution.

FIGURE 8 - Depiction of Stir Design 1 functionality improvements. An adjustable base

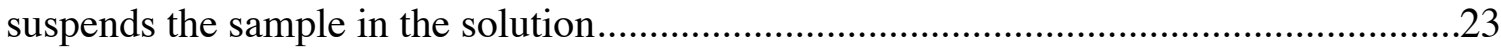

FIGURE 9 - Laser cutout of the adjustable base in Stir Design 1 with slot mounts for the sample and cathode. Distance designations and laser cut accuracy ensure error minimization and sturdy functionality.

FIGURE 10 - Vortex flow present within a beaker solution agitated via a magnetic stir bar. From Halász (Halász et al., 2007).

FIGURE 11 - Flow Design 1 overview with major features, solution cooling condenser and linear flow polishing chamber.

FIGURE 12 - Flow Design 1 (and 2) EP polishing chamber. An open topped, straight walled, custom made glass beaker design, allows electrolyte to flow around the sample through an inlet and outlet during EP.

FIGURE 13 - Flow Design 1 condenser. Although a condenser is typically used to condense a gas into a liquid, Flow Design 1 utilized a condenser as an all glass, liquid cooled radiator, acting as a chemically resistant and easily cleanable method of cooling the EP solution. The condenser was specially modified to include hose barb connectors.

FIGURE 14 - Flow Design 2 notable functional and performance improvements. ......... 28 FIGURE 15 - Flow Design 2 condenser similar in purpose to the Flow Design 1 condenser (Figure 13), but with enhanced cooling performance given that it is a longer, helical condenser.

FIGURE 16 - Rendering of the thermocouple implemented in Flow Design 2. The custom made thermocouple features a stainless steel construction, a chemically resistant coating, 
and a bent neck that reaches above the top of the polishing chamber in order to maintain a low profile.

FIGURE 17 - Close-up of the sample rotation mechanism introduced in Flow Design 2 highlighting main design features. Current is passed through a rotating metal axel to the part through motor brushes held by FDM brush holders.....

FIGURE 18 - Gwinstek PSW 160-14.4 constant power supply implemented within Flow Designs 1 and 2. Featuring USB and GPIB interface controls, the power supply adds long term functionality, allowing control within LabView. As in this project, the power supply is many times the most costly single component of an electropolishing system.. 33 FIGURE 19 - Customized Labview Virtual Instrument (VI) based upon the Gwinstek PSW 160-14.4 VI. Functionality added included simple waveform output control, visual temperature monitoring, and the ability to record data............................................ 34 FIGURE 20 - National Instruments cDAQ-9174 used to connect sensors and components to the custom LabView VI. The DAQ connected the thermocouple to LabView, allowing

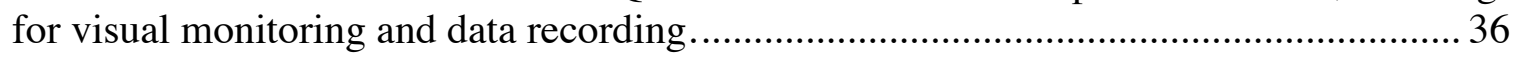
FIGURE 21 - Masterflex L/S digital peristaltic pump used to circulate the electrolyte... 37 FIGURE 22 - Neslab EX-110 water heating/cooling pump used to control the temperature of the by controlling the temperature of water that was sent through the Flow Design condenser. 38 FIGURE 23 - WEP PS-302D DC power supply used to power the rotational motor in Flow Design 2. 39 FIGURE 24 - Flow Design 2 and supporting components overview. The systemic layout of components is by design, as they are located in regards to their most desired location, least desired location, most desired neighbor and overall functional value. .... 39 FIGURE 25 - Experiment Flow Chart presenting overall methodology of progression from experiments to analysis.

FIGURE 26 - Experiment designs for both Stir Design and Flow Design experiments. Both experiment setups included a multiple number of finite level factors. FIGURE 27 - Current/potential plot of voltage ramping experiments designed to find a current limiting plateau for Titanium as well as provide insight into the experiment design setups.

FIGURE 28 - Time, Distance VS Ra plot comparing the impact of differing polish times and inter anode/cathode distances at constant temperature and voltage. Bar colors

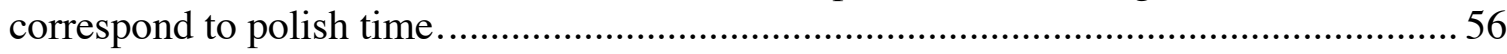

FIGURE 30 - Stir Design factors experiments ANOVA..............................................58 FIGURE 29 - Probability plot of Stir Design factors experiments Box-Cox transformed

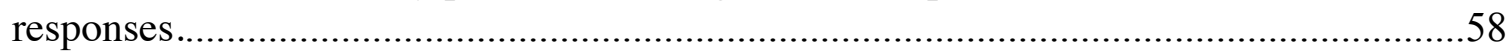

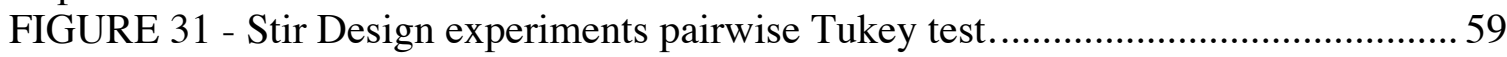

FIGUER 32 - Main effects plot of Box-Cox transformed Stir Design experiment responses.

FIGURE 33 - Interaction plot of Box-Cox transformed Stir Design experiment responses

FIGURE 34 - Time, Volts, Temp VS Ra plot comparing the impact of differing time, volts and temp at a constant distance. Bar colors correspond to polish time. 
FIGURE 35 - Flow Design factors experiments ANOVA.........................................64 FIGURE 36 - Probability plot of Stir Design factors experiments Box-Cox transformed

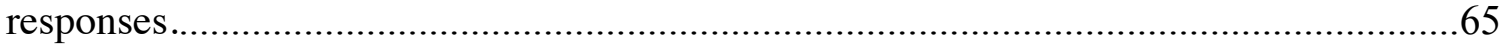

FIGURE 37 - Flow Design experiments pairwise Tukey test. .................................. 65

FIGURE 38 - Main effects plot of Flow Design experiment responses ...........................66

FIGURE 39 - Interaction plot of Flow Design experiment responses........................... 67

FIGURE 40 - Percent change via Time, Volts and Temp plot comparing percentage of Ra and change from original weight. Bar colors correspond to polish time........................ 69 


\section{INTRODUCTION}

\subsection{Thesis}

In the effort to improve the surface finish of EBM AM Ti6Al4V (Ti-6Al-4V), Electropolishing (EP) is considered due to its relative importance and limited understanding. While EP is an existing method for surface finish improvement, it is not a highly common surface finishing method compared to machining, particularly applied to AM parts. With further study of the EP, better knowledge might be gained towards the EP of Powder Bed Fusion (PBF) AM manufactured parts by attempting close inspection of the general and associated challenges. Relevance and value of research have been maintained by focusing on the EP of a challenging, rough surface produced by an AM process with promising part performance characteristics, EBM, and studying the EP of a popular AM material, Ti-6Al-4V.

\section{$1.2 \quad$ Brief History of AM}

As a manufacturing method, Additive Manufacturing (AM) came about as a natural product of both the growing demands of Computer Aided Manufacturing (CAM) and the growing capability of Computer Aided Design (CAD), made possible by increasing computing power. As CAD improved, more advanced designs were made possible, meeting the advanced modeling requirements needed to make AM a reality. Like any new technology, it is sensible that AM technology was used in its infancy to replace existing manufacturing methods that would receive the most benefit at the time. One such 
early implementation was in the case of prototyping. AM technologies greatly accelerated the creation of prototypes, originally coining the term AM lived under for many years, Rapid Prototyping (RP), a ground breaking advancement in R\&D manufacturing capabilities (Prinz et al., 1997). The benefits AM provides towards prototyping are numerous, including reduced time from conception to testing, cost savings, cost reduction via reduced manufacturing time, improved performance characteristics via advanced designs (Wu et al., 2015), overall process improvement by increasing the rate of prototype production and reducing lead time (Thomas and Gilbert, 2014), and lastly greatly reducing the cost of producing molds and dies (Kruth, Leu, and Nakagawa, 1998). Since the beginning of AM in the 1980s, companies such as the Ford Motor Company began utilizing AM for the manufacturing of prototype parts (Ford, 2014). With the advancement of AM technology, the use of AM has begun to extend well beyond prototype manufacturing and into the manufacturing of production components, establishing the term $\mathrm{AM}$ as a legitimate manufacturing method and no longer simply Rapid Prototyping (Gibson, Rosen, and Stucker, 2015). By industry, AM has recently shown predominant potential in consumer products and electronics, automotive, medical and aerospace, together totaling up to $80 \%$ of the total revenue of US made AM products (Ford, 2014). Within these industries, AM is of special interest towards improving overall product value by replacing and/or improving existing components and subcomponents with parts having higher performance per unit volume, time or cost (Gao et al., 2015, V.Wong and Hernandez, 2012). 


\subsection{Powder Bed Fusion AM}

Of the existing AM processes, Powder Bed Fusion (PBF) strongly contributes to the above needs, not only for its ability to create accurate, fully dense parts that exhibit high stiffness and strength (Gao et al., 2015), but more importantly for its ability to build such parts using metal powder. Of the materials being utilized in AM, metal remains to be one of the best materials in terms of performance characteristics. This fact, in conjunction with the pressing need to innovate existing metal components and improve manufacturing methods (Thomas and Gilbert, 2014), creates a strong interest in PBF AM within a number of industries, specifically aerospace, medical and automotive (Gao et al., 2015), as evident by the overwhelming percentage of AM sales propagating from these industries (Ford, 2014).

The two predominant PBF AM processes used in industry are Selective Laser Melting (SLM) and Electron Beam Melting (EBM). In all PBF processes, a number of steps are repeated in a cycle until a part is completed. First, a leveled bed of powder is melted in specific regions using a focused high energy source, then, a fresh layer of powder is spread on top (and leveled), and lastly, specific regions are melted again as the process is repeated. In an SLM process, a laser is articulated using mirrors in order to fuse the metallic particles together in specific regions, whereas in EBM, an electron beam is articulated using an electromagnetic field to perform the same task. As such, given that the articulation of the electron beam in EBM does not require any moving parts, there is a superb speed advantage over SLM as it is rate limited by mechanical mirrors to perform 
scans (Bhavar et al., 2015). EBM, being less accurate, also exhibits a rougher surface finish than SLM (Bhavar et al., 2015).

Over the history of metals manufacturing, PBF AM is a relatively new method. As such, understanding of PBF built parts is developing as studying the unique internal structure and properties of PBF AM parts is challenging (King et al., 2015). Inconsistent production quality, lack of standardization, confidential and proprietary manufacturer developed powders and processes and high costs of powder materials are a few reasons adding to the limiting of the number of materials available that are both used in conventional manufacturing and are also viably implementable within metal PBF AM (Ford, 2014). Of the three most common alloyed metals that stand out for their use concurrently in AM as well as in conventional manufacturing, Steel alloys, Inconel, and Titanium alloys, the Ti6Al4V (Ti-6Al-4V) Titanium alloy is the most popular. Ti-6Al-4V is highly desirable for its high strength, lightweight and low density, low coefficient of thermal expansion and high performance temperature, properties highly suitable for general aerospace applications, spacecraft applications and other high performance applications (Rawal, Brantley, and Karabudak, 2014). Ti-6Al-4V is prominently used within both EBM and SLM.

\section{$1.4 \quad$ Post Processing Surface Finish in AM}

Generally, these processes are being made more valuable by improving the performance of the machines, improving the quality of parts, but viable post-processing methods are also crucial towards improving part quality (Mani et al., 2015, Jadhav and Mankar, 2010). Surface roughness, an imperfection shared by both SLM and EBM 
(Loeber et al., 2011, Edwards, O'Conner, and Ramulu, 2013), is well known to reduce fatigue life, a characteristic that is crucial in components subjected to cyclic loading (Ford, 2014, Jadhav and Mankar, 2010, Mani et al., 2015). In order for AM components to be considered for use in dynamic environments, such as within aircraft engines, surface finish must be held in equal regard in $\mathrm{AM}$ as in conventional manufacturing. AM parts have shown high sensitivity under dynamic loading due to not only internal pores, but also surface finish acting as stress concentrations (Mani et al., 2015). Fatigue performance of AM Ti-6Al-4V parts has been shown to be reduced by up to $80 \%$ of conventionally manufactured $\mathrm{Ti}-6 \mathrm{Al}-4 \mathrm{~V}$ parts, with the fatigue life limiting factors being firstly surface finish and secondly porosity imperfections (Edwards, O'Conner, and Ramulu, 2013).

\subsection{Innovation in Post Processing in AM}

As in the past, the emergence of new technologies has created the need for new ways of solving existing problems, as it has been said by Albert Einstein, "We cannot solve our problems with the same thinking we used when we created them." Similarly, as AM parts are created in a different and new way than that of traditional, subtractive manufacturing, via processes such as machining, different and possibly new methods may be required for refining surface finishing in AM parts. In AM, part complexity can be greatly increased and manufacturing limitations removed. Surface finish improvement is no new problem and can be a challenging prospect even when performed on traditionally manufacturing parts. Now that AM parts can be created without the use of common methods used for improving surface finish, such as machining, they like wise 
cannot, many times, be machined, for example, to refine surface finish in the case of intricate internal channels and complex, locally fragile lattice structures. Even if an AM part could be post process machined, this would only limit the usefulness of AM, nullifying much of the advantage of using AM (Weller, Kleer, and Piller, 2015, Edwards, O'Conner, and Ramulu, 2013). Given that such parts, intended to be machined during post processing would need to be designed with this in mind, this likely negates the need to use AM. While abrasive flow machining allows for hidden features to be finished, it introduces specific challenges along with its advantages, such as requiring complex, expensive set up, limitation of part design needed to withstand the high pressure of abrasive flow, and challenges in evenly polishing surfaces (Kakde et al.). Using EP, it is possible to improve the surface finish of cavities not easily reachable using standard machining (Taylor et al., 2013). Where machining is not possible on AM parts, EP can be performed on Ti-6Al-4V, albeit traditionally using very hazardous electrolytes, some containing hydrofluoric acid (HF). However, currently a substantially less hazardous, likewise more easily implementable, non-HF, anhydrous, alcohol based Ti-6Al-4V compatible EP electrolyte now exists and shows promise (Tajima et al., 2008, Taylor et al., 2013).

\subsection{Focus of Work, Electropolishing of EBM AM}

This work focuses on the polishing of Ti-6Al-4V made in EBM for a number of reasons. Firstly, EBM produces Ti-6Al-4V parts of lower internal defects than SLM, resulting in parts with higher performance characteristics (Loeber et al., 2011). In EBM, a vacuum surrounds the Ti-6Al-4V, greatly limiting the oxygen content reaching the highly 
reactive Ti-6Al-4V material during the build, mitigating expected reduction in mechanical performance caused by the introduction of oxygen (Loeber et al., 2011). SLM does not perform builds within a vacuum, but rather in a chamber filled with an inert gas. While this greatly reduces the presence of oxygen in the build area, there is no better safeguard against oxygen existing in the chamber than in a vacuum chamber fully flooded of oxygen. Furthermore, while both SLM and EBM processes introduce residual stresses in parts due to rapid heating and cooling induced by either the laser or electron beam, EBM maintains a much higher build chamber temperature, reducing the magnitude of change in temperature and likewise lessening residual stresses in the part (Bhavar et al., 2015). Lastly, given that EBM produces parts of higher surface roughness than SLM, as mentioned above, any success made within a worst-case scenario should, intuitively, produce better results in a process yielding better initial surface finish, such as in SLM.

\subsection{Electropolishing}

Electropolishing (EP) is an electrochemical process in which the corrosion of an anode, resting in an electrolyte, is accelerated by the introduction of an electric current into an electrolytic cell. There are a number of primary components in an electrolytic cell, an anode, a cathode, a power supply, and an electrolyte accommodating the reaction (Perez, 2004). During electrolysis, current is applied through the anode, cathode and electrolyte, dissolving the anode and plating the cathode. In an electrolytic cell, two concurrent reactions occur, the electropolishing of the anode and the electroplating of the cathode. This likewise decides the placement of a specimen in question as an anode or cathode [FIGURE 1]. 


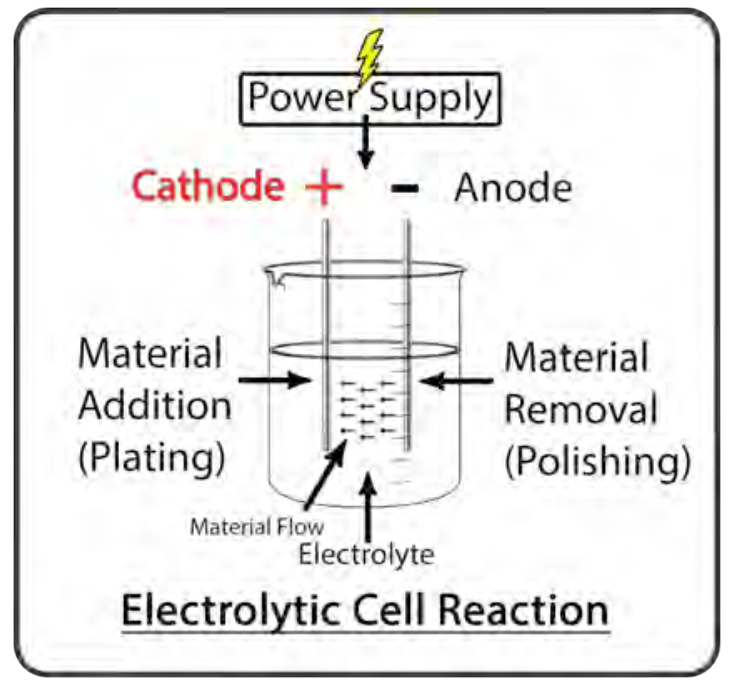

FIGURE 1 - Description of electrolytic cell reaction and main components.

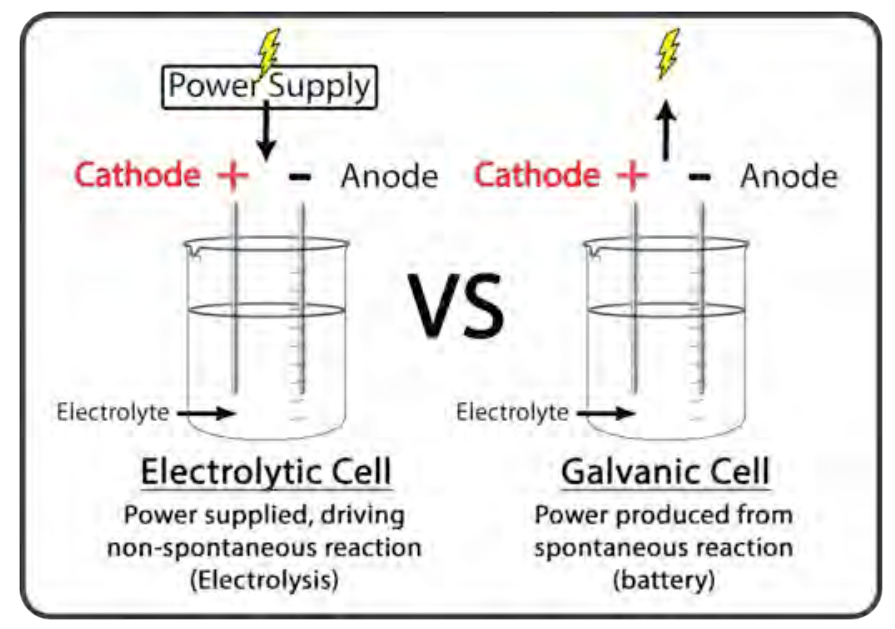

FIGURE 2 - Comparison of electrolytic cell versus galvanic cell 
An electrolytic cell is the opposite of a galvanic cell, a cell in which a spontaneous chemical reaction occurs, providing an electrical current [FIGURE 2], (Perez, 2004).

The mechanisms in action during EP make it particularly suitable for the EP of PBF AM parts. The most common method of improving a surface from a sandpaper like to a mirror-like finish is through using direct physical contact. As the surface progresses from rough to smooth the methods implemented change, beginning many times with machining, progressing to sanding or heavy buffing (or bead or sand blasting), and then fine polishing. Again, the disadvantage of machining, buffing, sanding, bead or sand blasting, and polishing is that these methods require direct physical contact, which is not always possible within AM parts, complex channels and structures, etc. Fortunately, EP, in principle, acts similarly to the existing methods, reducing firstly larger profiles and then reducing smaller features, doing so without direct physical contact.

As current passes through the electrolyte during EP, current lines concentrate on the peaks of surface profiles on the anode, causing EP to initially reduce the anodic surface locally at larger features. This is known as Macrosmoothing or Anodic Leveling, the reduction of large surface features with profiles in excess of $1 \mu \mathrm{m}$ [FIGURE $\mathbf{3} a$ to $b$ ]. After large surface features are reduced, finer surface features are polished during Microsmoothing or Anodic Brightening, the reduction of large surface features with profiles less than $1 \mu \mathrm{m}$ [FIGURE $3 \mathrm{~b}$ to c], (Landolt, 1987). 

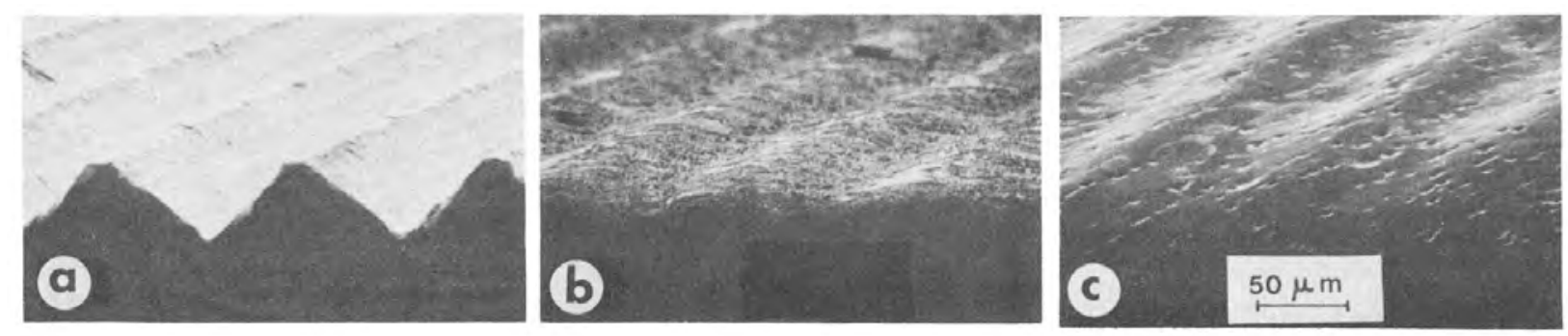

FIGURE 3 - Progression of electropolishing from (a) initial profile to (b) polishing done during Macrosmoothing and then (c) polishing done during Microsmoothing. Figure from Landolt (Landolt, 1987).

A surface film represses crystallographic etching during EP, allowing for brightening to occur instead (Hoar, Mears, and Rothwell, 1965). This mechanism is a major advantage of EP in relation to other post processing techniques given that the formation of the surface film, allows for micro, localized surface improvements. During simple chemical etching, the metal dissolution occurs more evenly across the features of the metal surface, both in valleys and on peaks, leading to a uniform profile reduction rather than leveling as made possible by the surface film in EP. However, managing this surface film properly is important if uniform polishing is to be achieved (Hoar, Mears, and Rothwell, 1965). This can be achieved through solution agitation, proper temperature control and by utilizing potentials within the current limiting plateau [FIGURE 5], (Datta et al., 1992).

The surface film attempts to follow the surface profile of the sample, but due to localized hydrodynamic effects does not perfectly correspond with the surface, but rather concentrates more heavily in the recesses of the surface features [FIGURE 4]. As the surface film inhibits polishing, and given that the surface film concentrates less on profile 
peaks than in troughs, a uniform, leveling dissolution is made possible. As long as the film is made to be thinner on the peaks of the sample surface features, then the current concentration on these peaks will remain higher than in the valleys given that the likelihood of dissolution concentration is increased per unit time. The net result of this is that the rate of dissolution is increased on the peaks as compared to the valleys, overcoming the natural tendency to profile reduction in chemical etching. Without proper solution agitation control, the surface film becomes too thick, either limiting polishing or inducing pitting (Cleric, Datta, and Landolt, 1984).

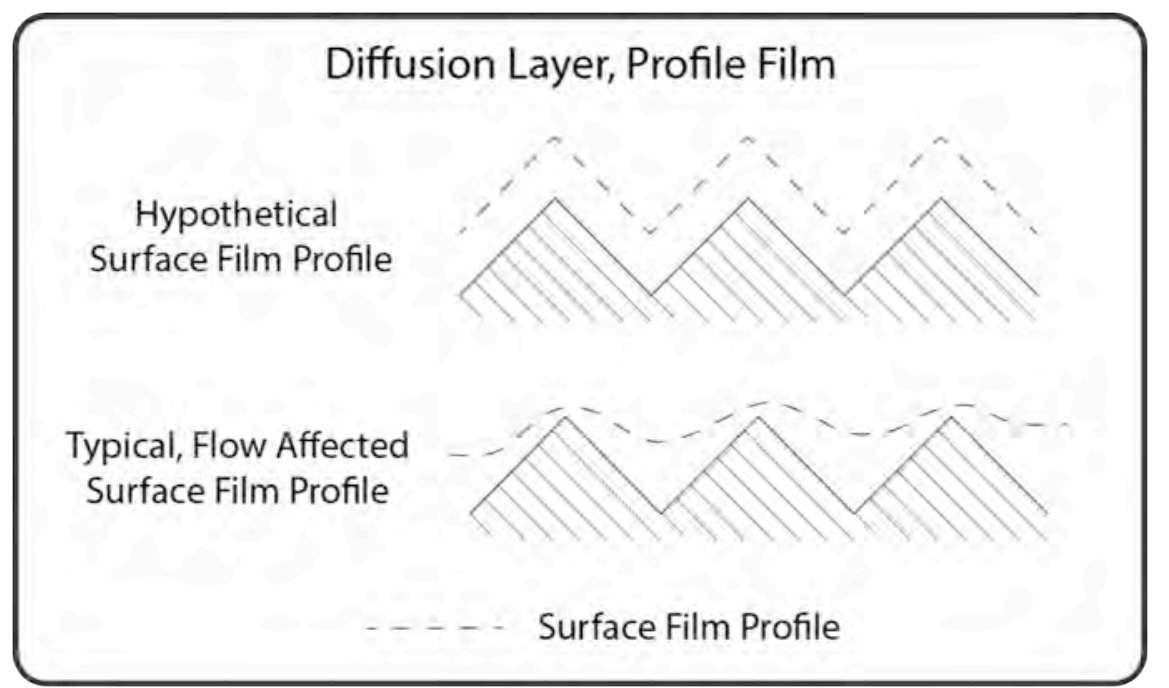

FIGURE 4 - Conceptual drawing of the diffusion layer profile film present during EP. While the hypothetical surface film profile closely follows the sample profile, the resultant surface film profile concentrates less densely at sample profile peaks due to localized hydrodynamic effects (Cleric, Datta, and Landolt, 1984).

Over-temperature during polishing can affect polish uniformity and possibly induce localized pitting effects by accelerating localized anodic dissolution (Cleric, Datta, and 
Landolt, 1984). Given that the EP process is exothermic, it is quite likely that temperatures will continue to rise during EP unless a proper heat sink is utilized. Any heat produced at a localized level that is not properly dissipated, by controlling the temperature of the solution as a whole, can increase the localized solution concentration at the sample surface, accelerating anodic dissolution (Cleric, Datta, and Landolt, 1984). Managing solution temperature can ensure that uniform leveling, via uniform leveling rates, is encouraged, by discouraging localized peaks in temperature.

There is a range of ideal potentials at which good polishing likely occurs. This range of voltages occurs within what is known as the "current limiting plateau". Within this range of potentials, it is common to discover an ideal potential(s) at which the best polish occurs [FIGURE 5], (Datta et al., 1992, Wagner, 1954). Above the current limiting plateau, increased film thickness reduces dissolution sites, increasing current localized current concentrations and inducing pitting. While ideal voltage levels differ for metal and electrolyte combinations, the current limiting plateau is a common EP characteristic (Cleric, Datta, and Landolt, 1984, Datta et al., 1992). 


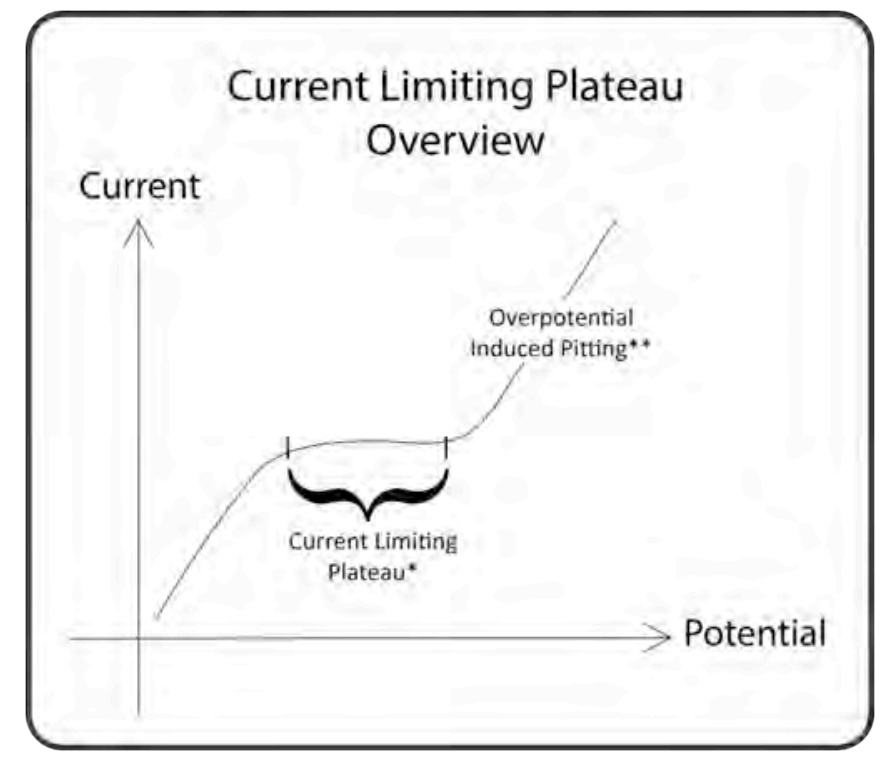

FIGURE 5 - Conceptual graph of the current limiting plateau commonly found during EP. At specific potentials, a current limiting plateau exists*. Within the current limiting plateau, a number of potential's exist that may return good polishing. Above the current limiting plateau**, pitting occurs rather than anodic brightening (Hoar, Mears, and Rothwell, 1965, Datta et al., 1992). 


\section{EXPERIMENTAL DESIGN SETUP}

\subsection{Systems Design Approach}

Throughout the project, special attention was paid to maintaining quality systems design, given the challenging nature of managing a research project. Research projects

are highly iterative, as paths are continually created, abandoned and revisited. In order to maintain steady progress and easily switch between paths, rework must be kept to a minimum as rework effectively doubles the expenditure of resources by repeating tasks. Just as in a tortoise and hare race, steady methodical design effectively out paces rapidly completed design that likely necessitates repeating. By paying careful attention to quality at both sub-component and systems level design, rework can be minimized, minimizing excess waste of the project's constraining factors and resources of time and cost.

\section{$2.2 \quad$ Systems Design Challenges}

Apart from maintaining quality in produced designs, doing so was challenging for a variety of reasons. An inherent problem is in handling the electrolyte solution. While the solution is far less toxic than traditional strong acids used to EP of Titanium and safe to touch, the solution is nevertheless corrosive and has strongly negative affects on materials it contacts, particularly metals. This meant that all components intended to handle the electrolyte had to be highly chemically resistant, limiting the materials able to be used, with minimal issue, to materials such as stainless, polypropylene and glass. 
These three materials are not inexpensive and working with them is difficult. Stainless performs decently, but is not transparent, difficult to modify for obvious reasons (requires welding fine, small pieces), and is expensive. Polypropylene is highly chemically resistant as well as transparent, but difficult to construct with as most glues are not compatible. When initially designing Flow Design 1, all components handling the solution consisted of polypropylene, however when proceeding to assembling the components, it was quickly discovered that most strong glues are not capable of fusing polypropylene. Since polypropylene is highly chemically resistant, it is difficult to find glues, chemicals in their own right, that are able to fuse the material. This prompted a forced redesign using glass. Glass is transparent and excellent for use with chemicals, but perhaps the most difficult of the three aforementioned materials to work with, as all components made using this material must be custom worked by a skilled craftsman. With the construction of these materials as a limiting factor in design, creative thinking was required to accelerate design despite this and maintaining low cost. The cooling method implement in the flowing solution designs required cross purposing and modifying an existing tool in chemistry, a condenser. The polishing chamber used in the Flow Design(s) required straight walls to encourage a linear solution flow. Straight walled, square shaped, glass beakers are not as common as round glass beakers because they are difficult to manufacture, making them very costly to make in house. An old square shaped glass chemical beaker was discovered on a shelf at the custom local glass shop that parts were already being fabricated/customized at. This was cut in half and repurposed as the polishing chamber, saving considerable cost. 
Other than integrating the electrolyte into designs, many other components required careful planning. Designing a system to handle a liquid, apart from EP, can be a challenging prospect. Particularly in the flow designs, ensuring that the tubing, glass components and fittings were watertight, easy to attach and detach, and reliable was a minor challenge. While some standards exist for such attachment methods, deciding on the method for ensuring a waterproof fit required forethought. Initially the glass components were to require costly custom fittings to clinch down on the tubing, but it

was soon decided that paying extra upfront cost to custom install barb fittings would reduce overall cost and maintain better functionality. Preventing and/or mitigating a failure of the solution handling components was an important detail not to be overlooked, as a failure of these components could endanger many of the neighboring expensive electronic components in the overall system, such as the computer running LabView, the power supplies, the peristaltic pump and the heating/cooling loop pump [FIGURE 24].

\subsection{Design Quality Metrics}

While the experiment builds were likely to be one of a kind, single production runs, the designing was performed with a number of systems design elements in mind. In order to minimize wasted time and cost while maintaining quality, experiment builds were designed with the following in mind, versatility, modularity, ease of use, repeatability, robust design, efficiency, and overall functional value [TABLE 1 ]. 
TABLE 1 - Design quality metrics used to ensure resultant system design quality

\begin{tabular}{|c|c|}
\hline \multirow[b]{2}{*}{ Versatility } & Adjustability, accommodation of a wide operating margin \\
\hline & $\begin{array}{l}\text { Ex: Allows for a range of solution volumes, part sizes and shapes, } \\
\text { etc. }\end{array}$ \\
\hline \multirow[b]{2}{*}{ Modularity } & $\begin{array}{l}\text { Multiuse of components with overlapping, cross functional } \\
\text { compatibility }\end{array}$ \\
\hline & $\begin{array}{l}\text { Ex: Components integrable within designs and with other designs. } \\
\text { Allows for mixing and matching between designs, allowing for } \\
\text { "hot-swapping"and minimizing the need to perform total } \\
\text { redesigns. }\end{array}$ \\
\hline \multirow{2}{*}{ Ease of use } & $\begin{array}{c}\text { Usability. Easily adjustable, ease of } \\
\text { construction/deconstruction, and minimization of permanent } \\
\text { construction }\end{array}$ \\
\hline & $\begin{array}{l}\text { Ex: Use of nut and bolt assembly simplifies experiment prep, } \\
\text { operation and clean-up. Clearances are reasonable and } \\
\text { components are easily removable. }\end{array}$ \\
\hline Repeatability & $\begin{array}{l}\text { Easy to build, repair and copy, important for both for } \\
\text { minimizing downtime as well as improving value of results } \\
\text { (such as repeatability of experiments) }\end{array}$ \\
\hline
\end{tabular}




\begin{tabular}{|c|c|}
\hline & $\begin{array}{l}\text { Ex: Utilizing common building materials, making parts via laser } \\
\text { cutter or AM Fused Deposition Modeling (FDM), and minimizing } \\
\text { special order components. }\end{array}$ \\
\hline Robust & $\begin{array}{l}\text { Good durability and performance for reuse. Chemically } \\
\text { resistant materials and ease of cleaning. }\end{array}$ \\
\hline Design & $\begin{array}{l}\text { Ex: Glass, polypropylene, strong metal fittings, and sturdy } \\
\text { component mounts }\end{array}$ \\
\hline \multirow[b]{2}{*}{ Efficiency } & $\begin{array}{l}\text { An efficient use of resources. Time and cost minimized, via } \\
\text { minimizing required materials, enabling quick setup and } \\
\text { breakdown times, and utilizing good value materials and } \\
\text { components. }\end{array}$ \\
\hline & $\begin{array}{l}\text { Ex: Design build around affordable glass beakers, prefabricated } \\
\text { components and easily attainable hardware. Minimization of } \\
\text { sharp corners for ease of cleaning. Design for minimal required } \\
\text { solution for experimental runs. Minimized number of special order } \\
\text { components. }\end{array}$ \\
\hline Overall & $\begin{array}{l}\text { Mitigate value loss inherited through poor design, rather, do } \\
\text { the components work together to make a cohesive, practically }\end{array}$ \\
\hline Functional & useful design. \\
\hline Value & $\begin{array}{l}\text { Ex: The quality of the design is such that it can be legitimately re- } \\
\text { implemented if need be in the future, even if temporarily retired. }\end{array}$ \\
\hline
\end{tabular}




\section{$2.4 \quad$ Design Evolution}

Following the requirements dictated by research, each experiment build was designed to perform a defined set of tasks. While each iteration of the experiment builds was not identical, many core functionalities were passed along, and improved, from one design to the next [TABLE 2].

TABLE 2 - Overview of design evolution in terms of design improvements, design features and iterations.

\begin{tabular}{|c|c|c|c|c|c|c|c|c|c|c|c|}
\hline \multirow{3}{*}{ Design } & \multicolumn{7}{|c|}{ Task } & \multicolumn{4}{|c|}{ Functionality } \\
\hline & \multirow{2}{*}{$\begin{array}{c}\text { EP } \\
\text { On/Off }\end{array}$} & \multicolumn{2}{|c|}{ Temperature Control } & \multicolumn{2}{|c|}{ Solution Agitation } & \multicolumn{2}{|c|}{ Part Manipulation } & \multicolumn{2}{|c|}{ Data Recording } & \multicolumn{2}{|c|}{ Controls } \\
\hline & & Cool & Heat & Stir & Flow & Support & Rotate & Temp & Time & Temp & EP \\
\hline $\begin{array}{c}\text { Stir } \\
\text { Design } 0\end{array}$ & $\begin{array}{c}\text { Manual/ } \\
\text { Analog V1 }\end{array}$ & $\begin{array}{c}\text { Ice vla } \\
\text { Conduction }\end{array}$ & & $\begin{array}{l}\text { Stir } \\
\text { Bar }\end{array}$ & & $\begin{array}{c}\text { Submerged } \\
\text { Platform } \\
\text { V1 }\end{array}$ & & $\begin{array}{c}\text { Analog } \\
\text { V1 }\end{array}$ & $\underset{V 1}{\text { Analog }}$ & $\begin{array}{c}\text { Manual/ } \\
\text { Analog V1 }\end{array}$ & $\begin{array}{c}\text { Manual/ } \\
\text { Analog }\end{array}$ \\
\hline $\begin{array}{c}\text { Stir } \\
\text { Design } 1\end{array}$ & $\begin{array}{c}\text { Manual/ } \\
\text { Analog V1 }\end{array}$ & $\begin{array}{c}\text { Ice vla } \\
\text { Conduction }\end{array}$ & $\begin{array}{c}\text { Heat Plate } \\
\text { V1 }\end{array}$ & $\begin{array}{l}\text { Stir } \\
\text { Bar }\end{array}$ & & $\begin{array}{c}\text { Suspended } \\
\text { V1 }\end{array}$ & & $\begin{array}{c}\text { Analog } \\
\text { V2 }\end{array}$ & $\underset{\text { V2 }}{\text { Analog }}$ & $\begin{array}{c}\text { Manual/ } \\
\text { Analog } \\
\text { V1.1 }\end{array}$ & $\begin{array}{c}\text { Manual } f \\
\text { Analog }\end{array}$ \\
\hline $\begin{array}{c}\text { Flow } \\
\text { Design } 1\end{array}$ & $\begin{array}{c}\text { Automatic } \\
/ \text { Digital }\end{array}$ & $\begin{array}{c}\text { Tap Water } \\
\text { Circulatlon } \\
\text { via } \\
\text { Condenser } \\
\text { v1 } \\
\end{array}$ & $\begin{array}{c}\text { Integrated } \\
\text { V1 }\end{array}$ & & $\begin{array}{l}\text { Flow via } \\
\text { Peristaltic } \\
\text { Pump }\end{array}$ & $\begin{array}{l}\text { Suspended } \\
\text { V2 }\end{array}$ & & $\underset{\text { V1 }}{\text { Digital }}$ & $\begin{array}{c}\text { Digltal } \\
\text { V1 }\end{array}$ & $\begin{array}{c}\text { Automatic } \\
\text { /Analog }\end{array}$ & $\begin{array}{c}\text { Digltal/ } \\
\text { Automatic } \\
\text { Via } \\
\text { LabVlew } \\
\text { V1 } \\
\end{array}$ \\
\hline $\begin{array}{c}\text { Flow } \\
\text { Design } 2\end{array}$ & $\begin{array}{c}\text { Automatic } \\
\text { /Digital }\end{array}$ & $\begin{array}{c}\text { Tap Water } \\
\text { Circulatlon } \\
\text { vla } \\
\text { Condenser } \\
\text { v2 } \\
\end{array}$ & $\begin{array}{c}\text { Integrated } \\
\text { V1 }\end{array}$ & & $\begin{array}{l}\text { Flow via } \\
\text { Peristaltic } \\
\text { Pump }\end{array}$ & $\begin{array}{l}\text { Suspended } \\
\text { V2.1 }\end{array}$ & $\begin{array}{c}\text { Rotate } \\
\text { vla } \\
\text { Motor }\end{array}$ & $\begin{array}{c}\text { Digital } \\
\text { V1 }\end{array}$ & $\begin{array}{c}\text { Digital } \\
\text { V1 }\end{array}$ & $\begin{array}{c}\text { Automatic } \\
\text { /Analog }\end{array}$ & $\begin{array}{c}\text { Digltal/ } \\
\text { Automatic } \\
\text { Via } \\
\text { LabView } \\
\text { V1 } \\
\end{array}$ \\
\hline
\end{tabular}

As experiments were run using the designs and research was performed, major challenges were discovered and moderated as possible through design improvement. Generally, there were two major challenges discovered both in practice and in literature that had to be accounted for in the designs, the proper control of the solution flow and the solution temperature control during EP (Cleric, Datta, and Landolt, 1984). As such, throughout the evolution of the designs, the primary improvements and innovations focused on temperature control and solution flow. 


\subsubsection{Stir Design 0 Initial Design}

The initial experiment design accommodated the basic needs of an EP system, a glass beaker to hold the electrolyte and mechanisms to hold both the cathode and anode [FIGURE 6, FIGURE 7]. As the initial design and the first design implementing a

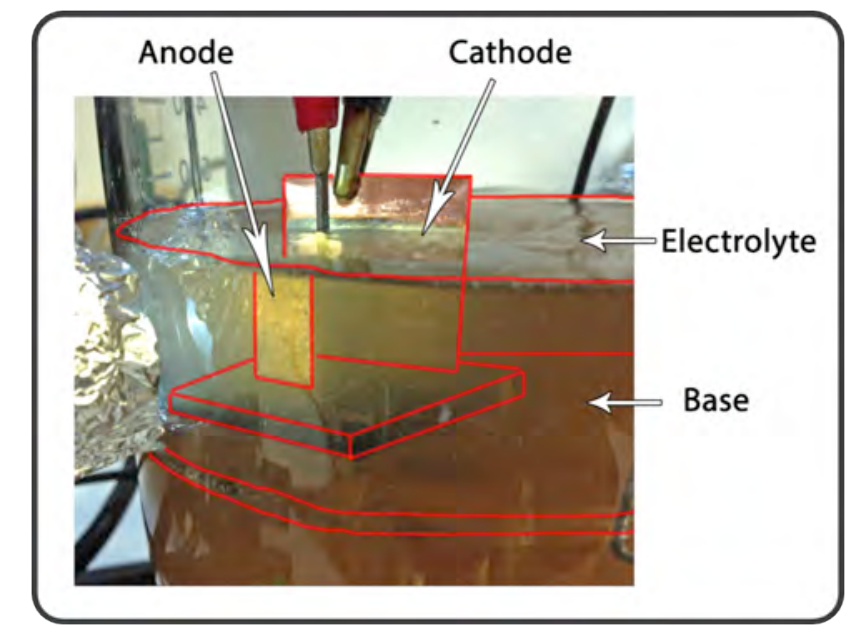

solution stir

FIGURE 6 - Side view of initial experiment design, Stir Design 0.

agitation method,

the design was labeled "Stir Design 0". 


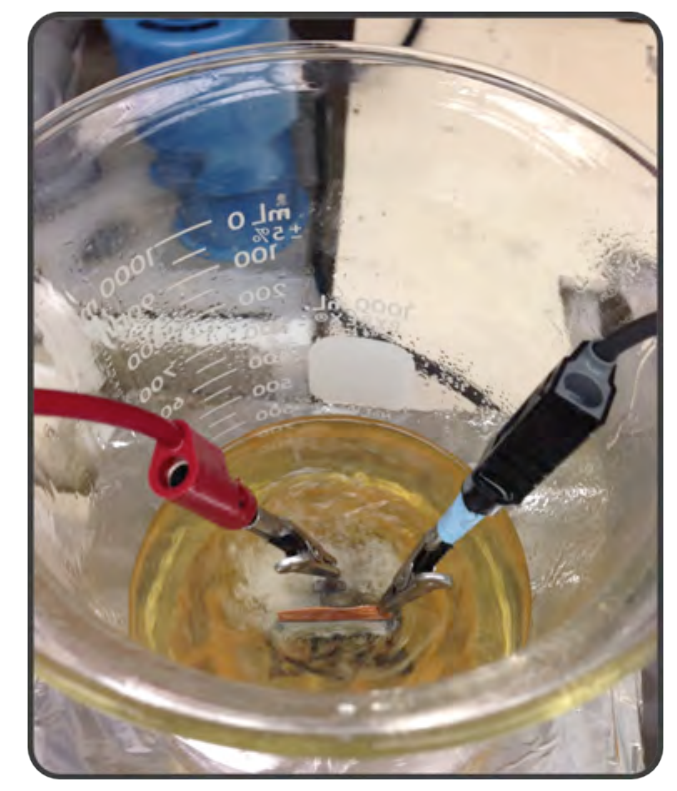

FIGURE 7 - Top view of Stir Design 0 showing anodic sample and cathode support submerged in solution.

The sample was held from beneath by a base platform that was submerged in the electrolyte solution throughout the duration of the polishing. Originally, Stir Design 0 did not include a stir bar, but a stir bar was soon added as research indicated that agitation of the electrolyte would be recommended to promote homogeneous, non-pitting anodic dissolution (Cleric, Datta, and Landolt, 1984).

\subsubsection{Stir Design 1}

In an attempt to mitigate extraneous factors as well as reduce random turbulence of the solution flow, Stir Design 1 improved upon the previous design by suspending the part in the solution. This eliminated extraneous materials, such as the base and wires holding the base in Stir Design 0, from resting within the solution during polishing. With Stir Design 1, only the anodic sample and cathode are in contact with the solution, with 
the exception of a thermocouple thermometer. Furthermore, the base supporting the sample in Stir Design 0 created a random turbulent solution flow around the sample during stirring. By suspending the sample, Stir Design 0 eliminated this and allowed for a more unobstructed flow being created in the cylindrical beaker by the stir bar [FIGURE 8]. 


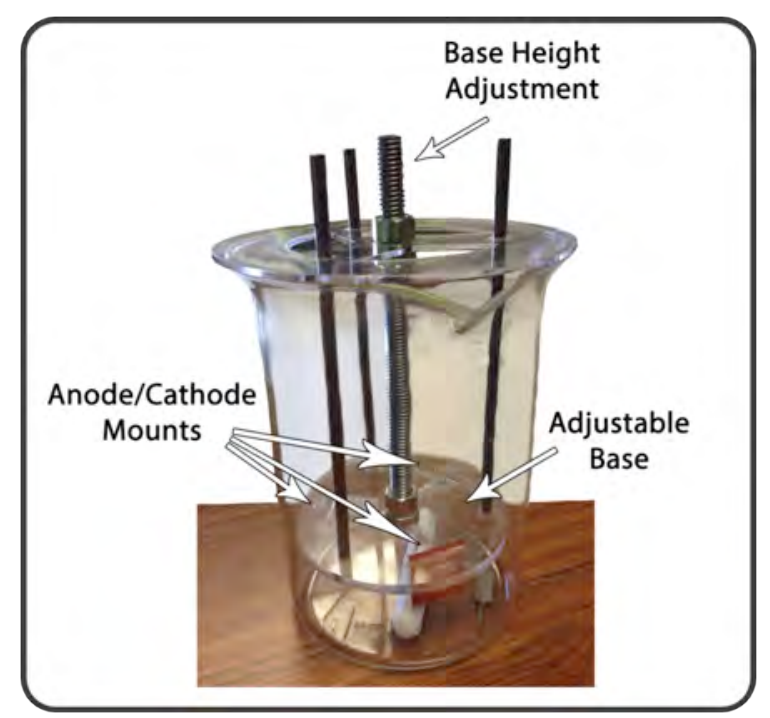

FIGURE 8 - Depiction of Stir Design 1 functionality improvements. An adjustable base suspends the sample in the solution.

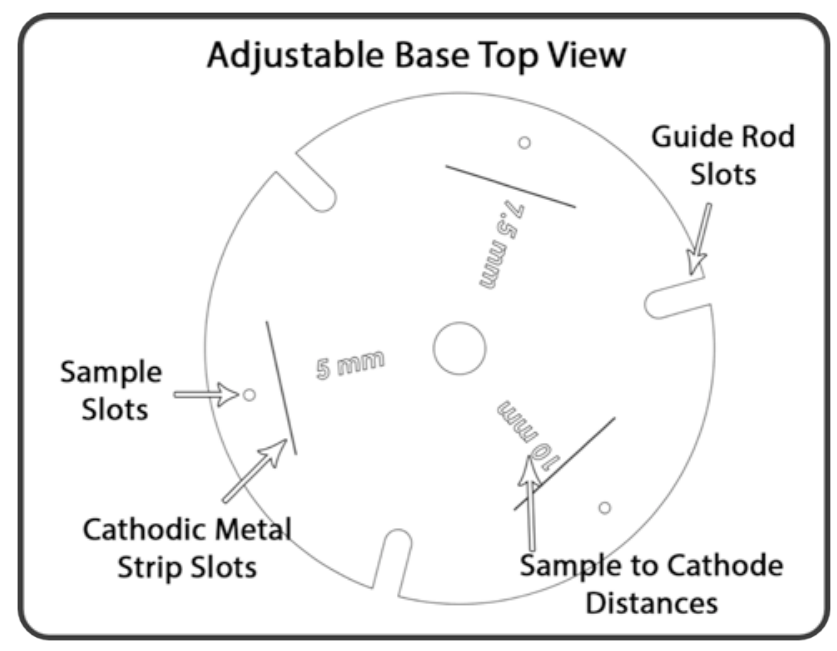

FIGURE 9 - Laser cutout of the adjustable base in Stir Design 1 with slot mounts for the sample and cathode. Distance designations and laser cut accuracy ensure error minimization and sturdy functionality. 
Apart from the above progressed capabilities, this design also added a number of efficient features to greatly improve usability and likewise minimize time used in preparation between experiment runs. The base was easily adjustable to accommodate for differing levels of solution if desired. The transfer of electricity to the sample and cathode was through the guide rods on the adjustable base instead of directly as in Stir Design 1 (FIGURE 6, FIGURE 7), a safety and reliability enhancement. The design featured three preset anode/cathode mount sets of differing distances. Utilizing laser cut anode/cathode mounts ensured accurate and snug securing of both the sample and cathode. Distances were designated with laser cut numbers in the base to eliminate confusion. As the most complex and core component of the design, the adjustable based needed to be easily replaceable if possible. This in mind, the base was laser cut out of house hold materials, allowing good repeatability for quick design adjustments and rebuild if need be [FIGURE 8].

\subsubsection{Flow Design 1}

While the stir bar solution agitation mechanism did provide for a regular flow pattern in Stir Design 1 as opposed to Stir Design 0, the path of such a flow is not simple. Using a stir bar in a beaker creates a fluid rotation that travels simultaneously circularly around the beaker as well as up along the side walls of the beaker and back down towards the center (Halász et al., 2007), [FIGURE 10]. 


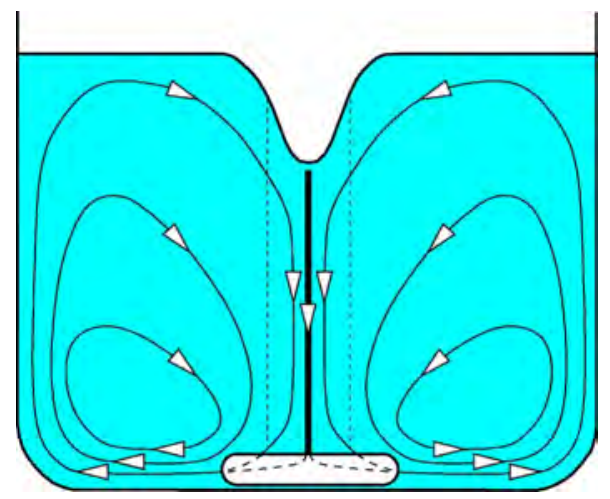

FIGURE 10 - Vortex flow present within a beaker solution agitated via a magnetic stir bar. From Halász (Halász et al., 2007).

Looking to further reduce complexity of the solution flow within the experiment design, a linear flow system was designed, Flow Design 1 [FIGURE 11]. In Flow Design 1, solution flow was created using a peristaltic pump [FIGURE 21]. Solution firstly enters the polishing chamber, where the sample is polished, passes through the condenser for cooling and lastly is circulated back into the polishing chamber.

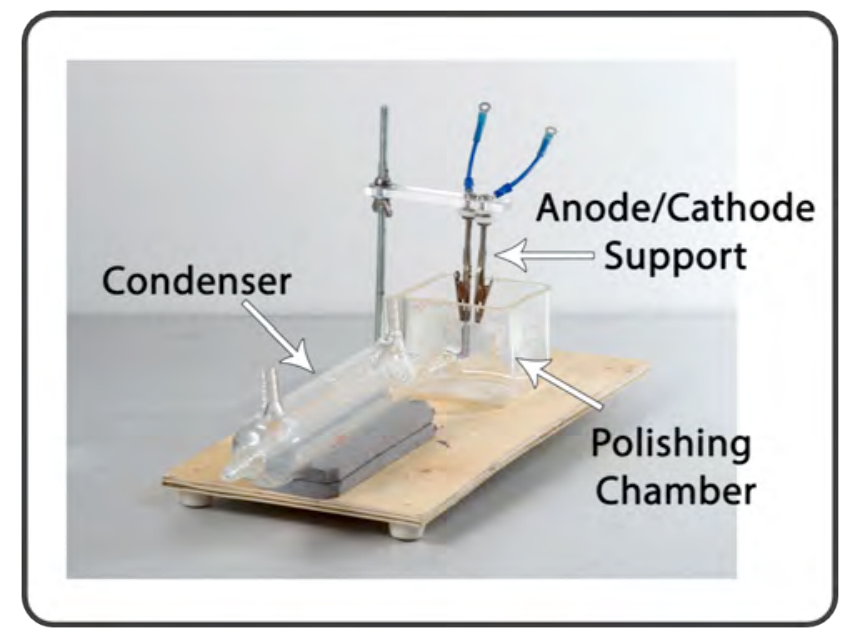

FIGURE 11 - Flow Design 1 overview with major features, solution cooling condenser and linear flow polishing chamber. 
The introduction of a straight walled polishing chamber reduced the complexity of flow found in Stir Design 1, approaching a more linear flow with the electrolyte entering and exiting the polishing chamber through an opposing inlet and outlet. The polishing chamber is the most costly and difficult to replace component in both Flow Design 1 and 2. The chamber was custom made from a rectangular beaker with glass hose barbs integrated into the walls. It is uncommon to find square shaped scientific glass beakers, the primary element for the high cost of the component [FIGURE 12].

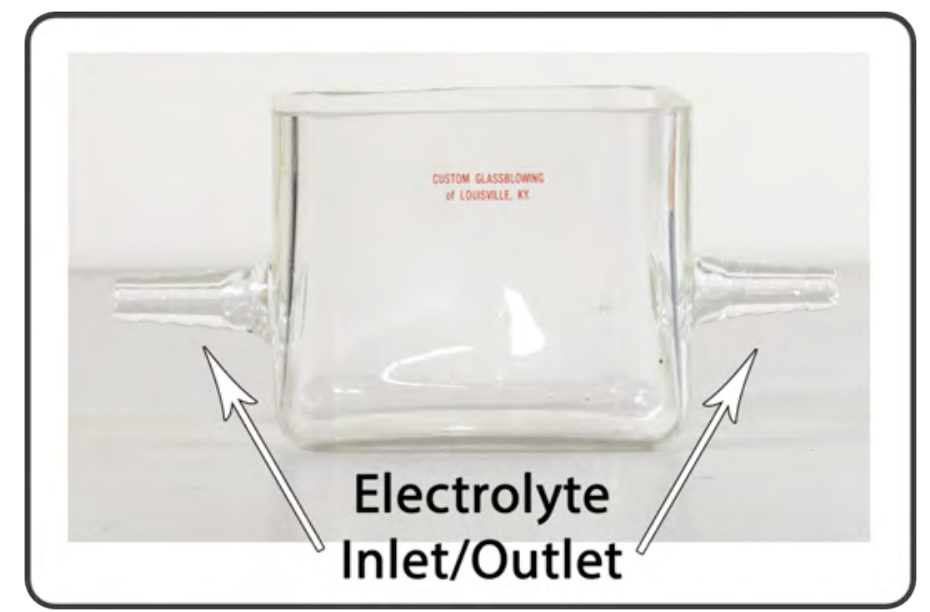

FIGURE 12 - Flow Design 1 (and 2) EP polishing chamber. An open topped, straight walled, custom made glass beaker design, allows electrolyte to flow around the sample through an inlet and outlet during EP.

Furthermore, given that control of the solution temperature during polishing had proven difficult, Flow Design 1 also integrated an improved cooling mechanism into the linear flow circulation loop. The conception of a linear flow system allowed for the solution to pass through a tube in a circuit, allowing for the following. 


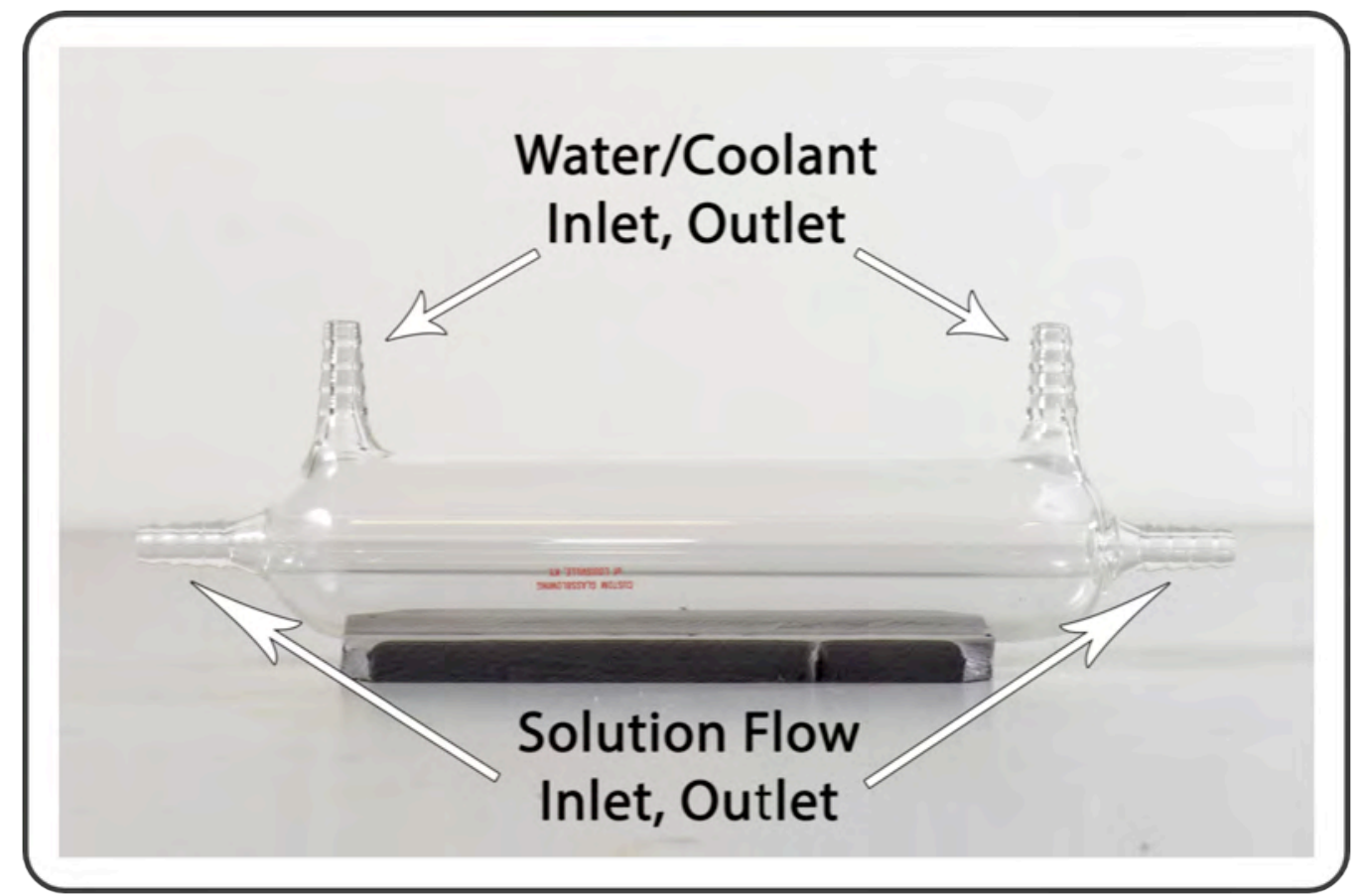

FIGURE 13 - Flow Design 1 condenser. Although a condenser is typically used to condense a gas into a liquid, Flow Design 1 utilized a condenser as an all glass, liquid cooled radiator, acting as a chemically resistant and easily cleanable method of cooling the EP solution. The condenser was specially modified to include hose barb connectors.

Initial ideas aimed towards devising some sort of air-cooled radiator to pass the solution through, however it was discovered that polypropylene, or sufficiently chemically resistant radiators, were not readily available. It was eventually decided to cross purpose a preexisting chemistry tool, a condenser, as it could act essentially as a liquid cooled radiator, and is also made of highly chemical and temperature resistant glass. In practice, the solution passes through the center of the condenser while water (or other coolant) is simultaneously circulated around the glass tube through which the solution is flowing [FIGURE 13]. The only modification performed on the condenser was the replacement of the traditional connection mounts with glass hose barb mounts. 
Improvements in temperature control by the implementation of a condenser improved the Flow Design by both lessened cooling time and adding automation of cooling, making gains in performance, efficiency and overall functional value.

\subsubsection{Flow Design 2}

The design advantages of Flow Design 1 were enhanced in Flow Design 2 with continued improvements in temperature control and part manipulation. A number of functional upgrades were made as well [FIGURE 14].

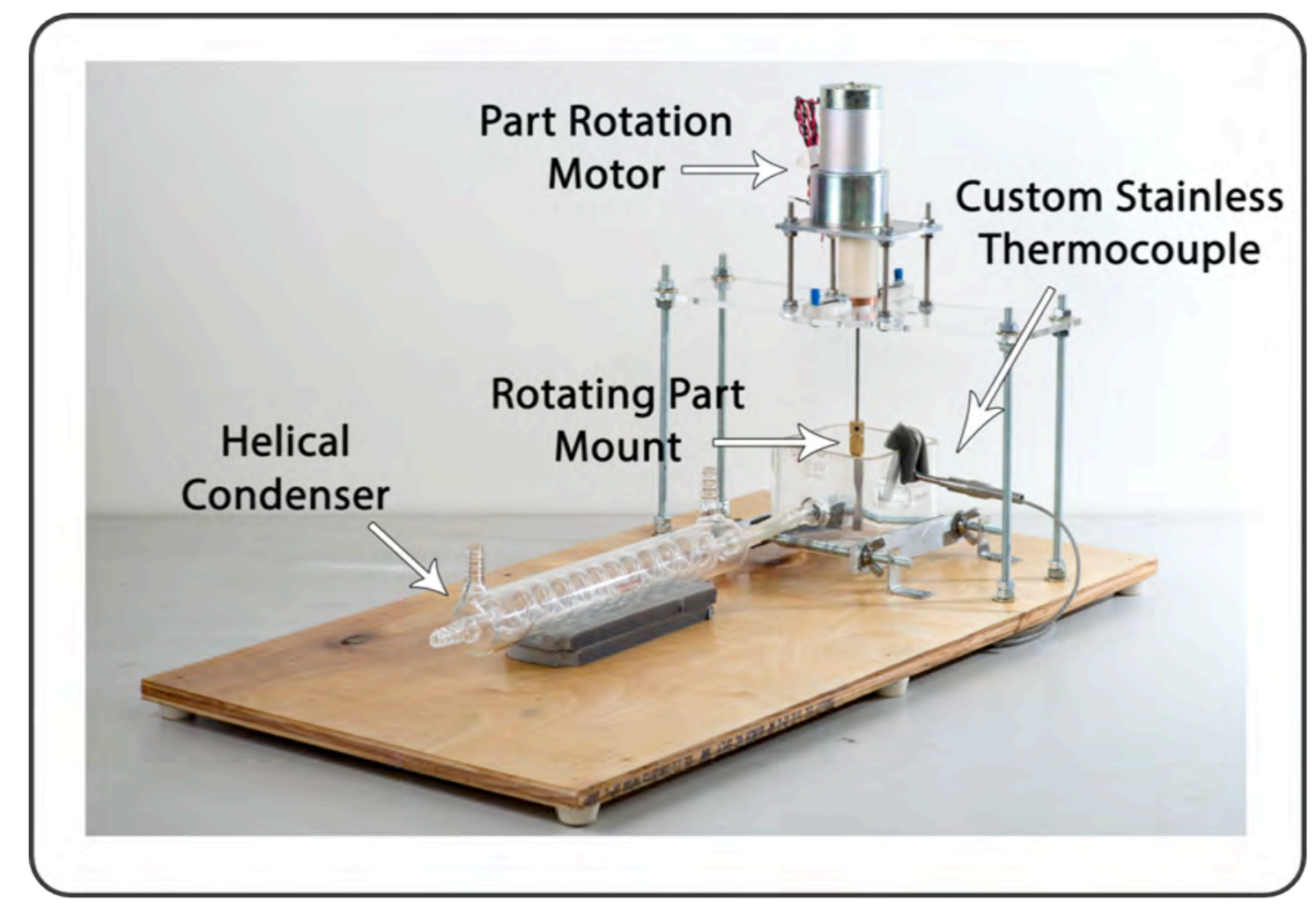

FIGURE 14 - Flow Design 2 notable functional and performance improvements. 
While the condenser in Flow Design 1 (FIGURE 13) performed its function well, better temperature control was still desired. The first condenser was replaced with a helical spiral condenser, improving both the conductive surface area and flow time of the solution through the condenser. Again, the condenser was custom modified to include barbed hose fittings [FIGURE 15].

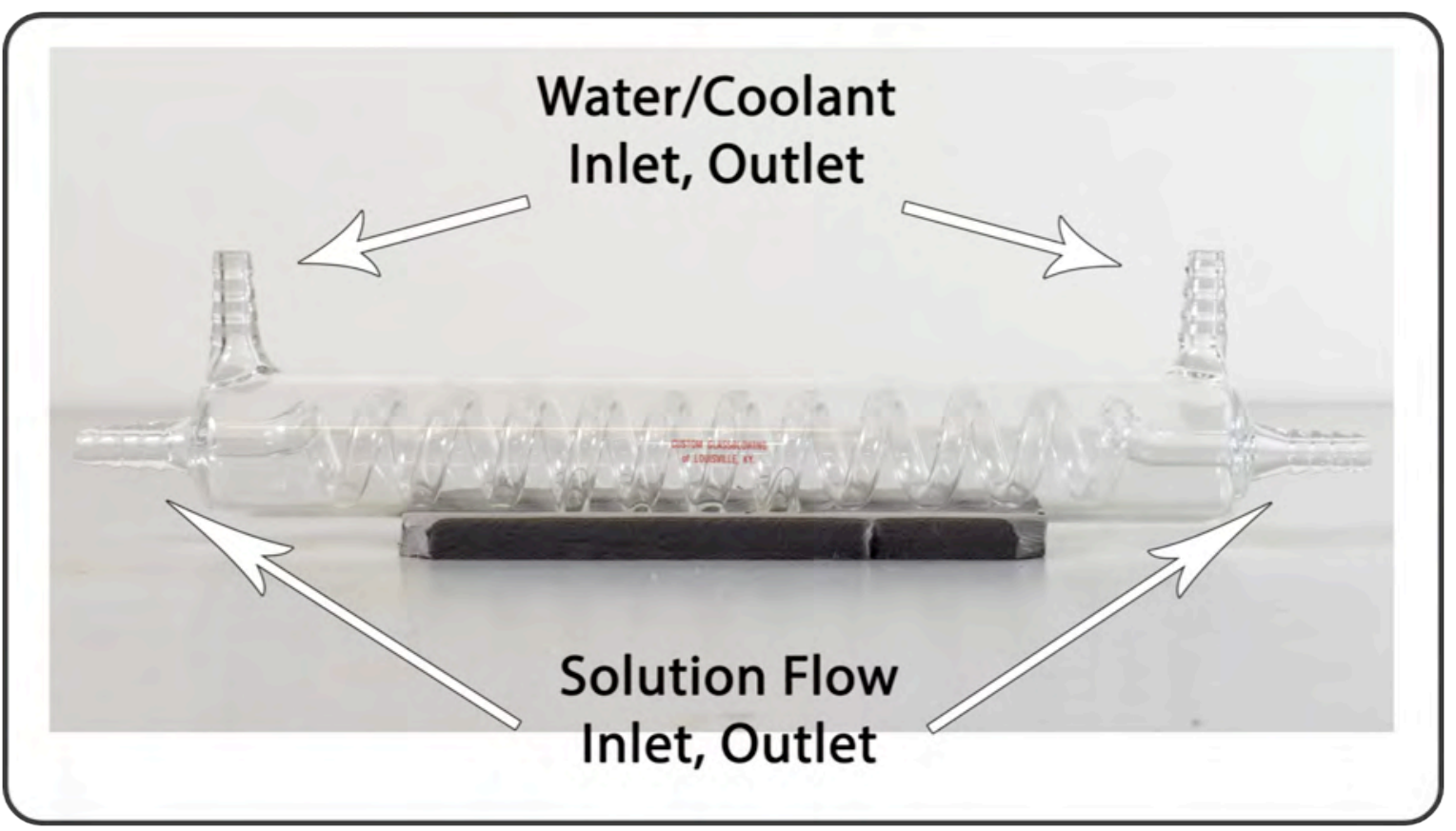

FIGURE 15 - Flow Design 2 condenser similar in purpose to the Flow Design 1 condenser (FIGURE 13), but with enhanced cooling performance given that it is a longer, helical condenser.

Temperature measurement was also enhanced through a custom made thermocouple. In the previous design signal noise became an issue as the temporary thermocouple Teflon wrap inevitably became saturated with the solution. This was compensated for by putting the thermocouple inside a glass tube, however the gap in between the 
thermocouple and the glass wall created a slight lag in readings. This called for a new more chemically resistant and robust thermocouple. Through a third party, a custom made stainless steel thermocouple was built and dipped in a chemically resistant coating to protect it from the solution and produce more accurate readings. The shape of the thermocouple was also specifically designed to reach around the top of the polishing chamber, and bend back down on the outside out of the chamber, remaining as unobtrusive as possible [FIGURE 16]. The thermocouple was connected to the system via a DAQ [FIGURE 20] to LabView [FIGURE 19].

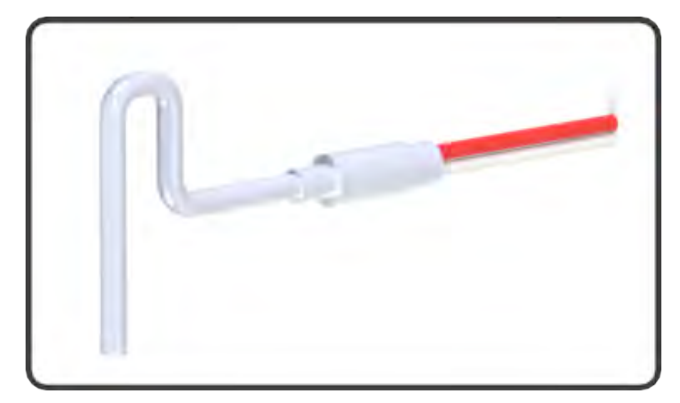

FIGURE 16 - Rendering of the thermocouple implemented in Flow Design 2. The custom made thermocouple features a stainless steel construction, a chemically resistant coating, and a bent neck that reaches above the top of the polishing chamber in order to maintain a low profile.

Perhaps one of the most important changes in the design was in part manipulation. It had been known from literature and affirmed through experiments, beginning with Stir Design 0, that fluid flow affects polish (Cleric, Datta, and Landolt, 1984). Stir Designs 0 and 1 did provide a fluid flow, but slightly irregularly given that the flow featured both a circular and vortex flow within a cylindrical beaker [FIGURE 10], (Halász et al., 2007). 
Flow Design 1 simplified the flow to a more linear type flow. Nevertheless, an immediate solution to further reducing the effects of the directionality of the flow would be to continually change the direction of the flow. What follows directly from this idea is a more simplified solution than moving the electrolyte flow direction, rather to manipulate the part in order to control the effect of the electrolyte flow across the sample.

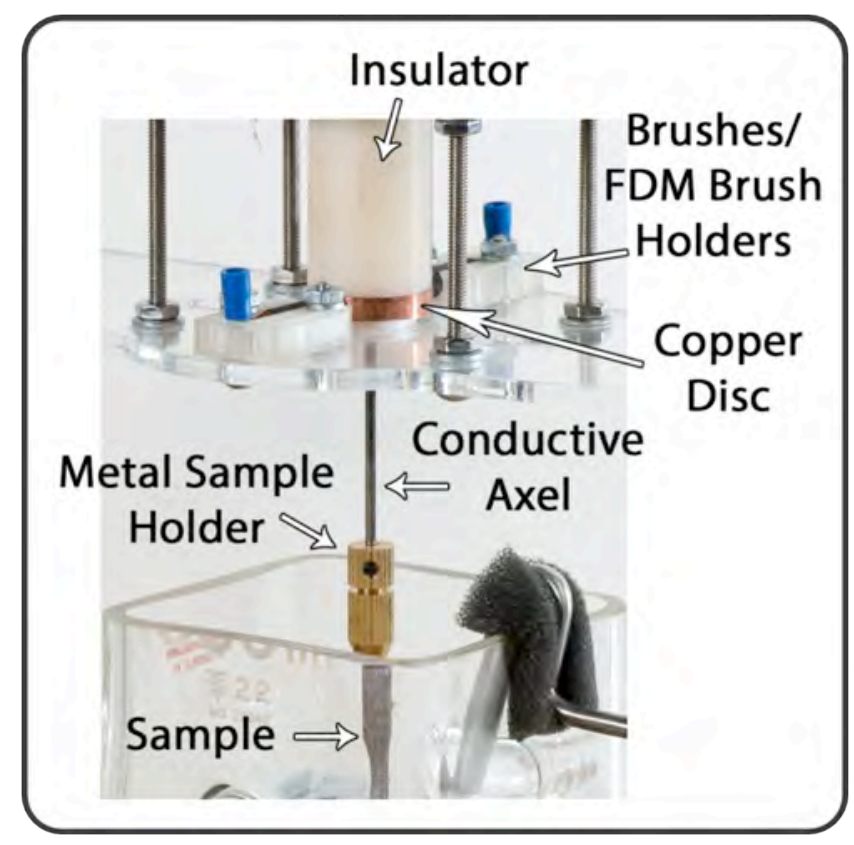

FIGURE 17 - Close-up of the sample rotation mechanism introduced in Flow Design 2 highlighting main design features. Current is passed through a rotating metal axel to the part through motor brushes held by FDM brush holders.

In Flow Design 2, the first method of part manipulation was introduced as a simple single axis sample rotation motion. The challenge of transferring a high current to the rotating part was overcome by using an all metal axel to hold and rotate the sample, insulating the axel where it connected to the motor, and then applying the current to the 
axel via motor brushes held using custom Fused Deposition Modeling (FDM), 3d Printed brush holders. A copper disc was press fitted onto the axel in order to increase surface area and improve electrical conductivity with the brushes. The entire rotational setup was constructed using components that made this subsystem versatile, modular, easy to use, repeatable, efficient, and functional. The setup could quickly change height by replacing the axel holding the sample. The mechanism holding the part is a cheap, non-custom, common drill bit holder that can hold a range of sample sizes, making the design usable on a number of sample types (tensile bar or a standard shaped coupon bar). The setup is also easily assembled by hand. The parts in the setup are quickly manufacturable using either FDM, or basic cutting, drilling and tapping of metal and plastic stock. Overall, the sample rotation setup adds value to the current design and lays the groundwork to future designs through the practical functionality of the design [FIGURE 17].

Other minor improvements included coating the base with polyurethane to speed cleanablity, lengthen design life, and improve general aesthetic appeal. As per design requirements the sample support sub system was made more robust. Comparing the platform suspending the sample in Flow Design 1 (FIGURE 11) to that of the platform suspending the sample in Flow Design 2 (FIGURE 14), it can be seen that the new fourpost design is more robust and offers expandability to add new features.

\section{$2.5 \quad$ Supporting Services/Devices}

Throughout the development of the designs, a number of non-design specific components were used. While not featured within the designs themselves, these 
components provide necessary supporting services for EP. Simple components such as stir bar plates and heater plates are not featured below.

\subsubsection{Power Supply}

In EP, the power supply is arguably the most important component, very much the engine of the system. Standing out from other components used in EP, the power supply easily stands out as the most expensive and difficult to obtain system component. The chosen power supply was the Gwinstek PSW 160-14.4, a LabView controllable constant power supply with a maximum voltage and amperage of 160 and 14.4 and features both USB and GPIB interfaces [FIGURE 18].

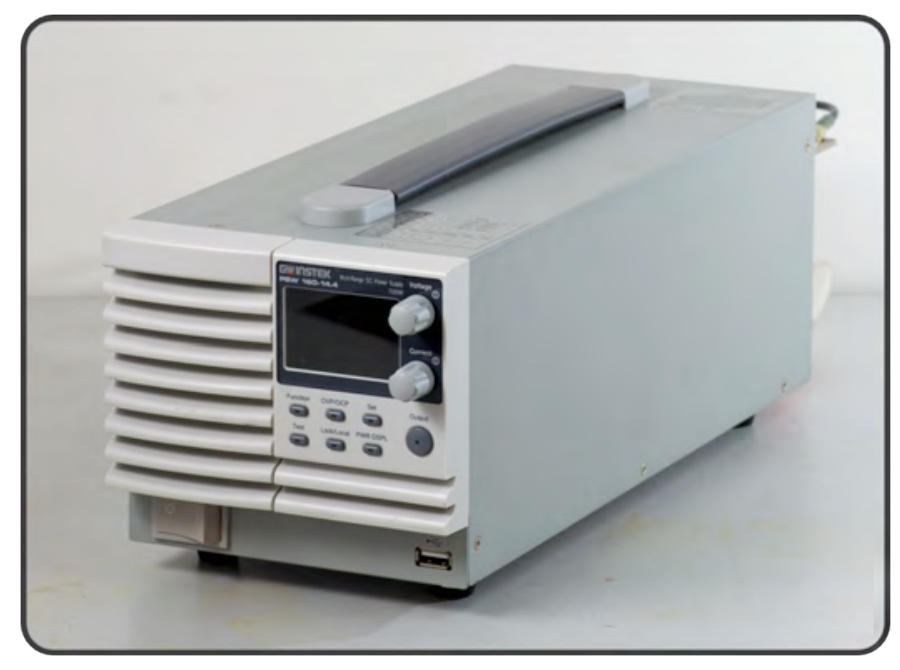

FIGURE 18 - Gwinstek PSW 160-14.4 constant power supply implemented within Flow Designs 1 and 2. Featuring USB and GPIB interface controls, the power supply adds long term functionality, allowing control within LabView. As in this project, the power supply is many times the most costly single component of an electropolishing system. 
The power supply shown was first implemented in Flow Design 1. Like all common power supplies utilized within EP, this power supply is a constant power supply meaning that the unit holds either voltage or amperage constant by modulating either voltage or amperage under a changing load. The power supply also features USB and GPIB inputs, allowing for a program based, LabView interface to control the power supply.

\subsubsection{LabView Virtual Instrument}

The value of the power supply can be greatly enhanced, or likewise limited, by the method used to control the power supply. The power supply used in the Stir Designs was an older model with only analog controls, unlike the digital, computer controllable Gwinstek PSW 160-14.4 [FIGURE 18].

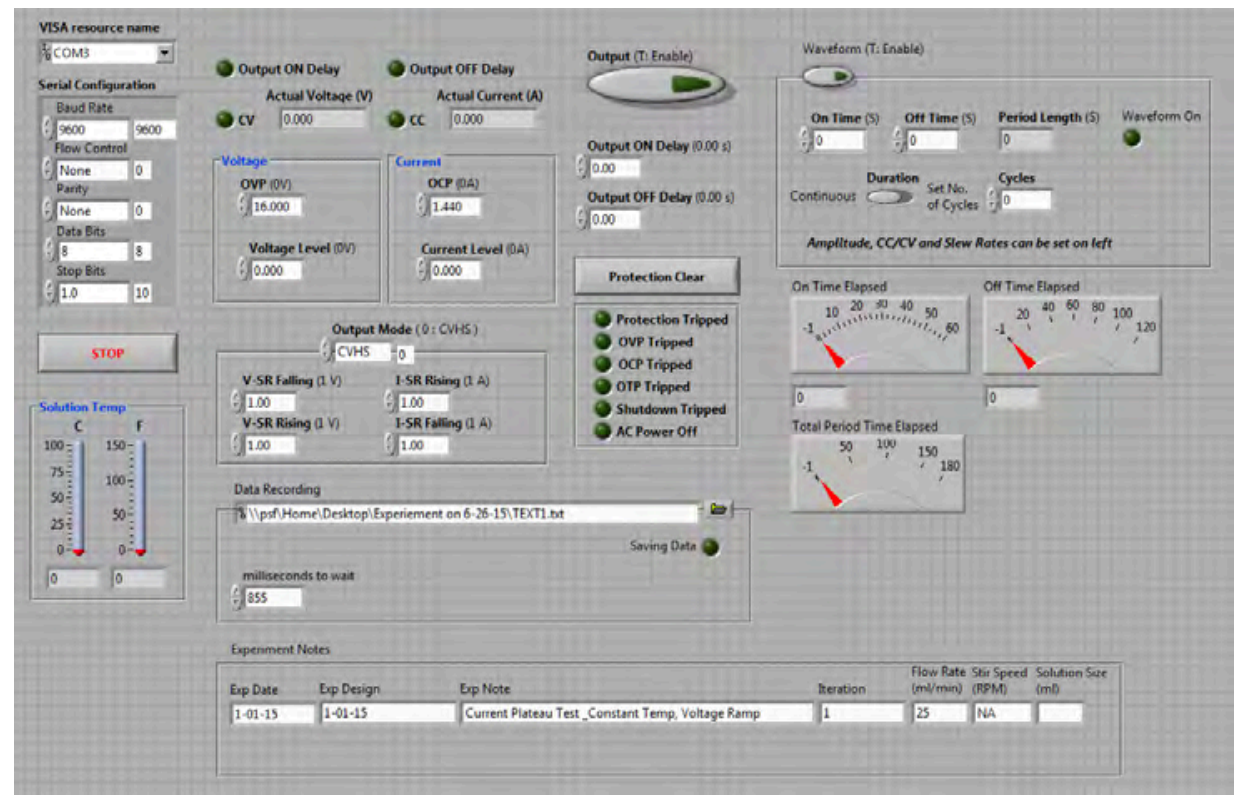

FIGURE 19 - Customized Labview Virtual Instrument (VI) based upon the Gwinstek PSW 160-14.4 VI. Functionality added included simple waveform output control, visual temperature monitoring, and the ability to record data. 
Extensive work was performed to add functionality within LabView. As the most expensive single component in the setup, the power supply was chosen carefully. When deciding upon a power supply, the most desirable options were firstly considered. Research had indicated that utilizing complex waveforms during EP could significantly improve polish quality (Taylor et al., 2013). Since the overall goal was to improve polish quality, this functionality was desired in a power supply, however, many of the complex waveforms found in literature required AC power supplies. Traditional DC power supplies can easily cost thousands, but AC power supplies exceed this cost by an order of magnitude. With only the DC power supply option being affordable, simplified waveform control was added within the LabView Virtual Instrument (VI).

The customized LabView VI [FIGURE 19] added functionality above basic controlling of the Gwinstek power supply. A simple waveform generator was added allowing set on and off cycles to be operated with gauges indicating on cycle time, off cycle time, and total cycle time remaining. Solution temperature monitoring was added, featuring both Celsius and Fahrenheit conversions. Perhaps the most important added function was the ability to write all data, temperature, time, voltage, amperage, and any associated notes, to a text file to be easily added later into Excel. A direct Excel export was attempted, but proved too cumbersome and unreliable. 


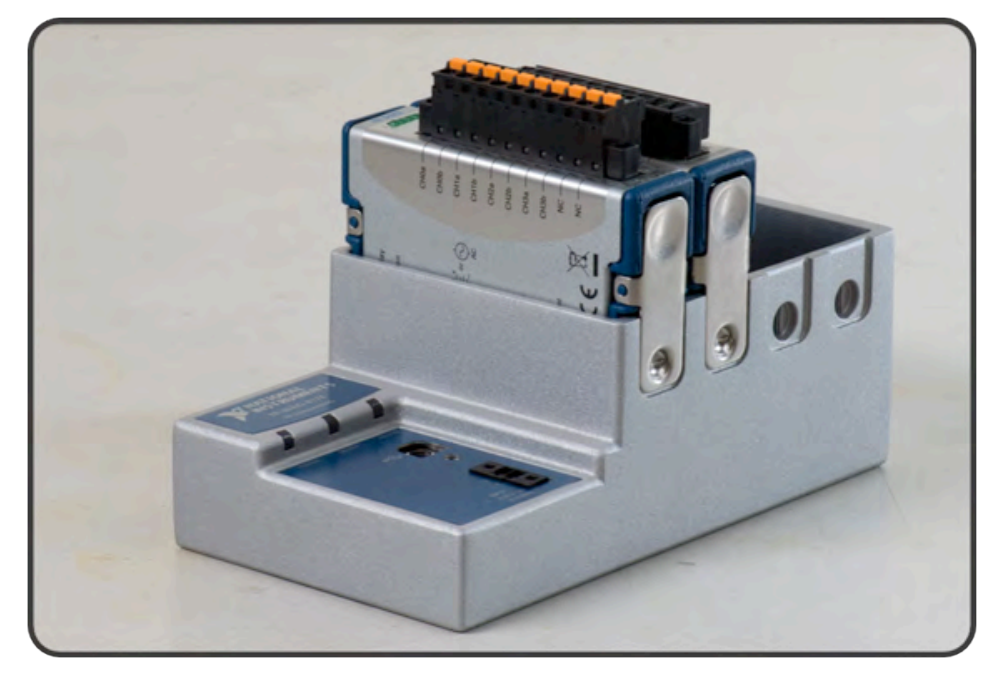

FIGURE 20 - National Instruments cDAQ-9174 used to connect sensors and components to the custom LabView VI. The DAQ connected the thermocouple to LabView, allowing for visual monitoring and data recording.

The addition of a Data Acquisition (DAQ) module [FIGURE 20] to the system, adds extended functionality when used in conjunction with the LabView VI. When connected to LabView, the DAQ provided a digital connection to components such as the thermocouple [FIGURE 16] or control of additional future components such as the peristaltic pump or rotational motor power supply [FIGURE 21, FIGURE 23].

\subsubsection{Peristaltic Pump}

Designing a system to pump a corrosive solution requires special design considerations. During the initial phase of Flow Design 1, a major hurdle to overcome was determining the mechanism to pump solution through the conceived solution flow loop. Typical pumps require pump components to come into contact with the solution. Polypropylene, or other highly resistant material, based pumps are not easily attainable, 
and for those that are available, their ability to be easily cleaned is limited. These considerations in mind along with the relatively low pressure and flow rates required made the implementation of a peristaltic pump a good fit.

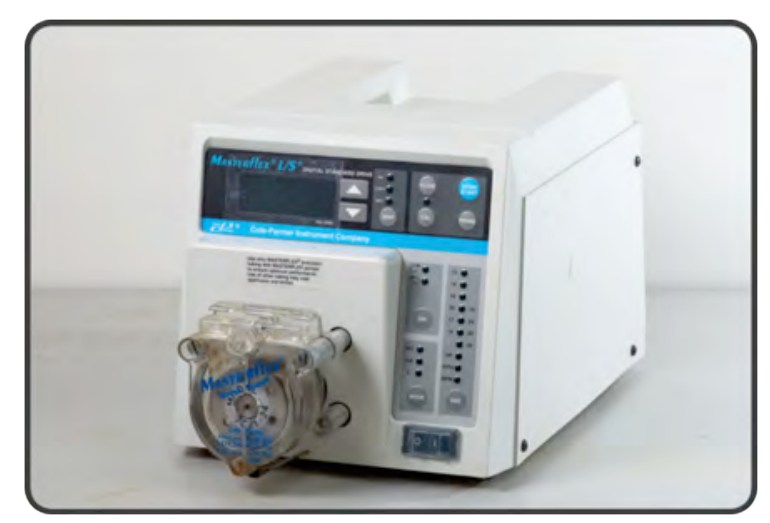

FIGURE 21 - Masterflex L/S digital peristaltic pump used to circulate the electrolyte.

The pump chosen for the task was a Masterflex L/S digital control peristaltic pump. Implementing a digital component over an analog one reduces the likelihood of random error from equipment settings.

\subsubsection{Heating/Cooling Loop Pump}

Controlling temperature in EP is important. Using a built in heater and external coolant source (such as cold water as was used), the Neslab EX-110 is capable of controlling the temperature, via thermostat, of a water bath. This water is then sent through the condenser to control the temperature of the solution. 


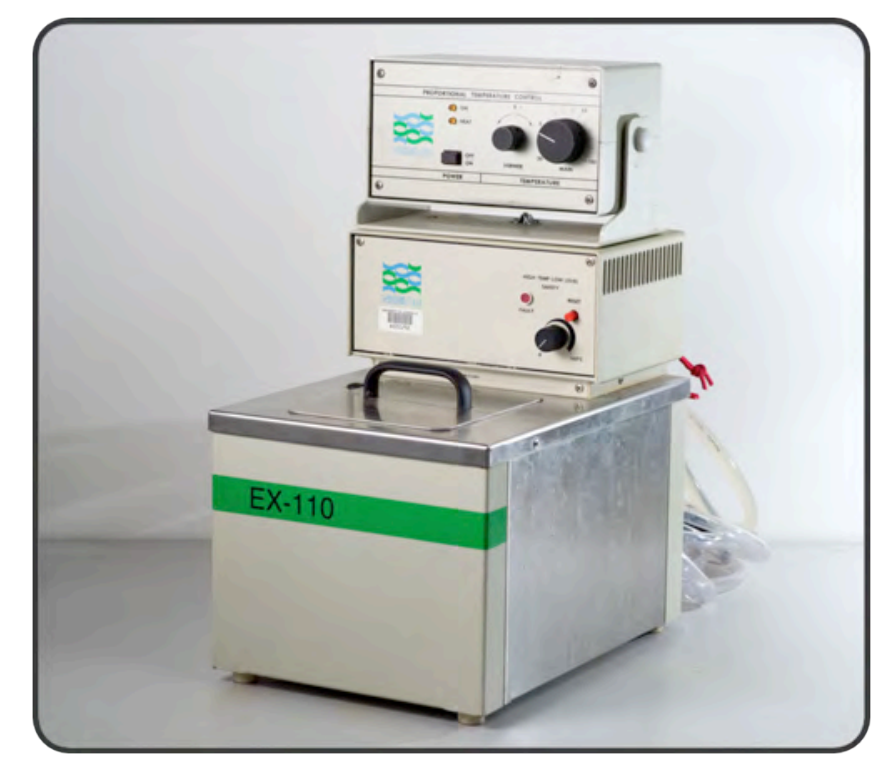

FIGURE 22 - Neslab EX-110 water heating/cooling pump used to control the temperature of the by controlling the temperature of water that was sent through the Flow Design condenser.

\subsubsection{Secondary Power Supply}

A secondary power supply was used to power the rotational motor in Flow Design 2. A WEP PS-302D DC power supply was chosen as it provided the ability to accurately modulate the rotational speed of the sample via digital controls. 


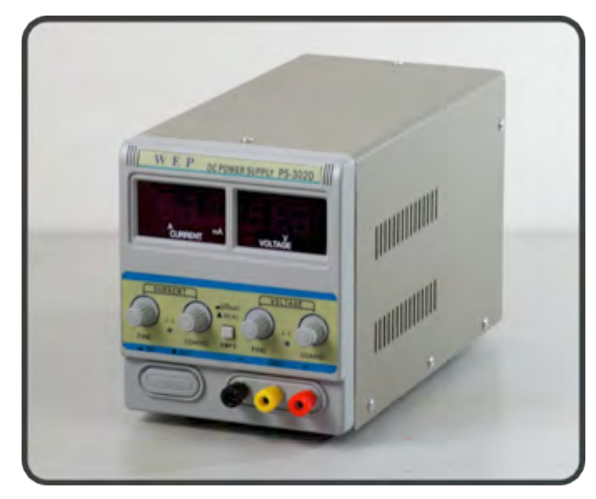

FIGURE 23 - WEP PS-302D DC power supply used to power the rotational motor in Flow Design 2.

\subsection{Integrated System Layout}

The integration of the above supporting components and current design yields the following setup. Only the most recent design is featured, but previous designs utilized many of the same supporting components and/or exhibited very similar design layout concepts [FIGURE 24]

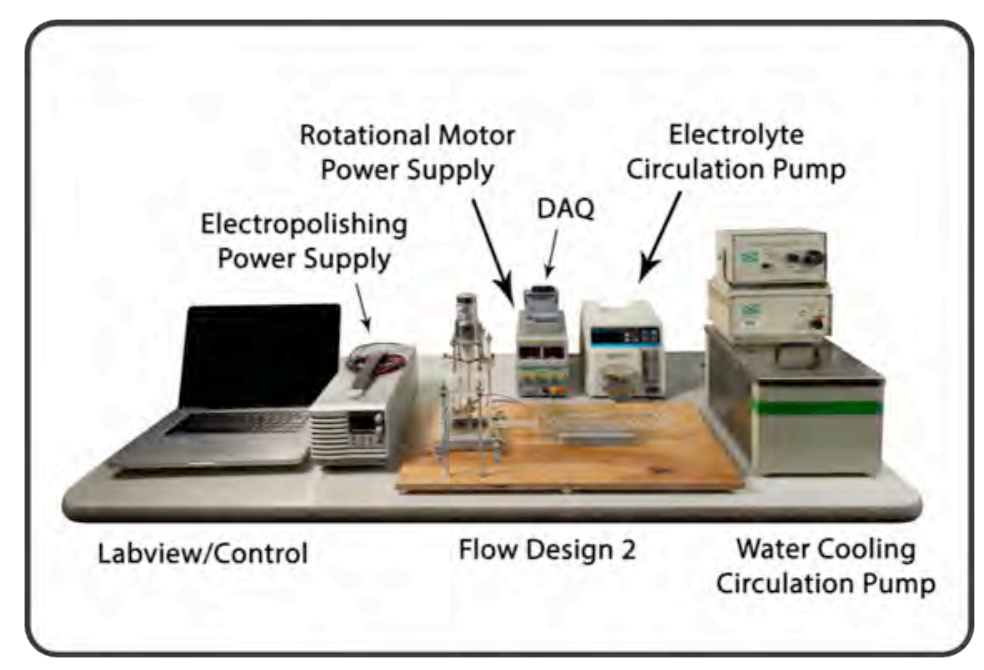

FIGURE 24 - Flow Design 2 and supporting components overview. The systemic layout of components is by design, as they are located in regards to their most desired location, least desired location, most desired neighbor and overall functional value. 
As evinced in the integrated system, all of the seven components in the system require electricity. This in mind with the fact that there is also the inclusion of two separate liquid circulation loops, water and the electrolyte, necessitated a careful system layout. While, the components are not connected in the image, in order to clearly distinguish the layout, the layout was intentional. Once the components are connected, there will be seven wires providing power to the components themselves, four wires connecting the power supplies to the EP and the sample rotation motor, two wires connecting from the thermocouple to the DAQ, two wires connecting the power supply and DAQ to the laptop computer, one tube (loop) connecting the electrolyte circulation loop and five tubes connecting the cooling/heating pump to the condenser, cold water supply and drainage source. In total, this results in 21 separate lines connecting the system. It can be noticed that this layout minimizes confusion of the lines by locating each of the components near their respective desired locations.

The peristaltic pump and cooling/heating pump needed to be close to the inlets and outlets of the electrolyte and water circulation loops, as they are located together on the right hand side of Flow Design 2 where the best access to the condenser is located. Putting these two devices together localizes the liquid handling area of the system, an advantage in shortening the physical size of the loops and decreasing spill impact during contingency. The drain on the floor beneath the system is beneath the table on the right hand corner, again optimal placement in case of a spill. The rotational motor power supply and DAQ are placed behind Flow Design 2 since this is an open space and it is 
buffered from the most likely to spill device, the cooling/heating pump, by the less likely to spill peristaltic pump. For future applications, it is likely that more precise control of the rotational motor will be desired. This functionality is easily added via LabView and the DAQ, placed near all the respective components, the motor, the rotational motor power supply and the computer.

The EP power supply is located within proximity to four components/locations in mind, the connection points for powering the EP of Flow Design 2, the laptop computer, the front of the table, and the left side of the table. In terms of overall safety considerations, the power supply is the most dangerous component of the system. Laying out the entire system as such minimizes the overlap, and thus entanglement, of the lines, most importantly the lines connecting the EP power supply to Flow Design 2. The reduced distance these lines have to travel greatly reduces risk of accidental touching during operation. Location the power supply next to the Laptop is a functional consideration in case there needs to be some troubleshooting of connectivity and also eases setup. Again, as being the most dangerous component in the setup, the EP power supply needs to be easily accessible. This is done by placing it at the front of the table, a functional safety consideration that puts the power switch on the front of the EP power supply in easy reach at the front of the table. Given that the operator will already be controlling and closely monitoring the experiment via the laptop computer, the concentration of the attention consuming controls is on this end of the table and the location of the switches on the EP power supply is again ideal. The EP power supple also acts as a last resort buffer to the laptop computer against any unlikely splashes, the laptop 
computer being the most sensitive component in terms of contact with liquid. Lastly, the location of the EP power supply on the left side of the table is the best in terms of distancing it from the cooling/heating loop as well as the right side of the table in general where the liquid circulation loops are located.

The widthwise orientation of Flow Design 2 is such that the flow of the solution and the polishing chamber are easily visible, allowing for future time lapse, video or other visual process monitoring and analysis. Again, within the lab, the entire experiment is located next to a drain, ideal for any cold water supply spills, a chemical hood, ideal for solution preparation, as well as a sink and compressed air supply essential for post process cleaning. 


\section{EXPERIMENT DESIGN}

Preliminary research focused on the expected factors affecting polish such that initial experiments performed could increase understanding and guide both the focus of subsequent research as well as the effectiveness of the experimental setup design. As it was found that polish is primarily affected by polish time, polish voltage and solution agitation (Landolt, 1987), the experiment designs were made to test for these factors. The following methodology was followed over the course of experiments using both Stir and Flow Designs [FIGURE 25].

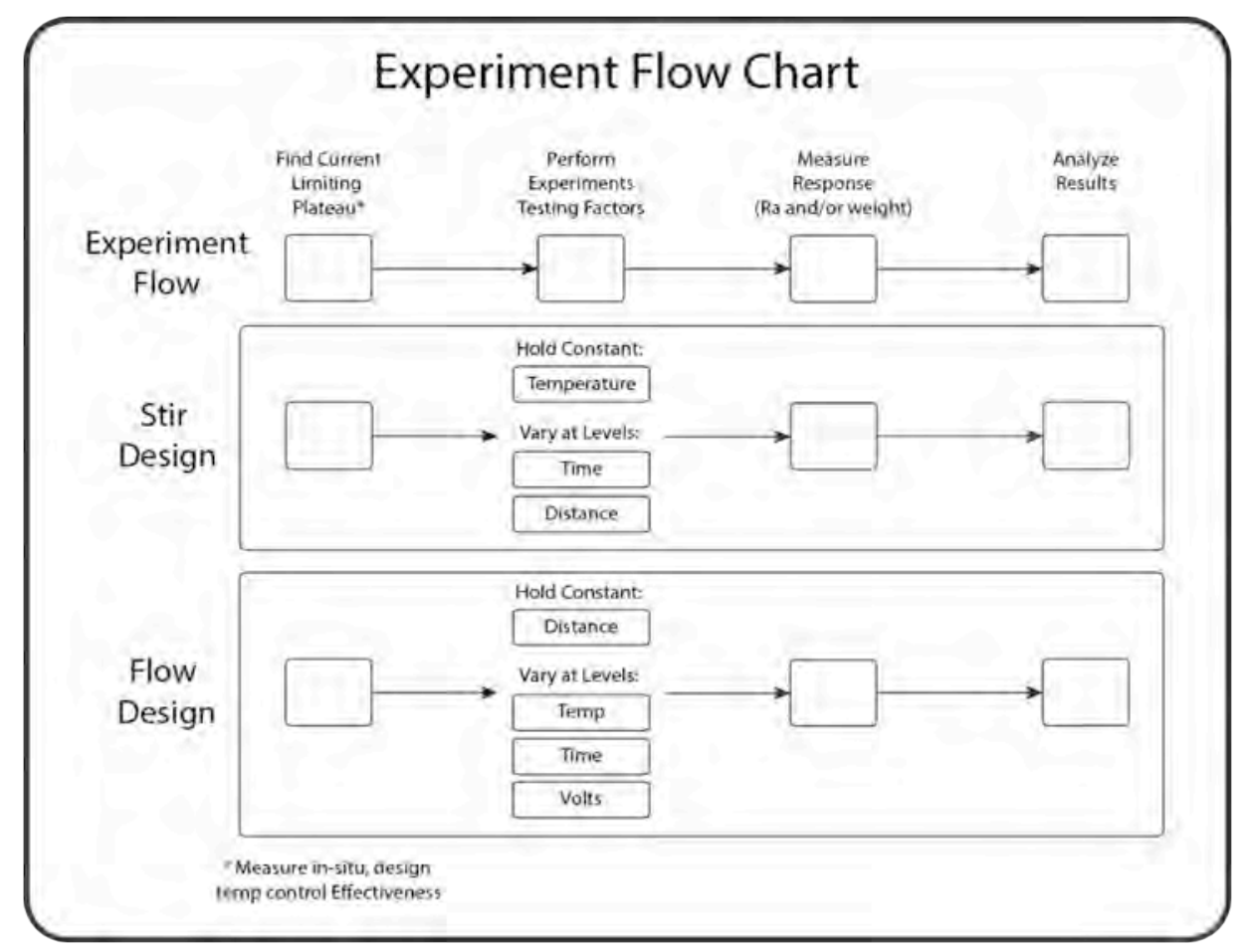

FIGURE 25 - Experiment Flow Chart presenting overall methodology of progression from experiments to analysis. 
As previously mentioned, it is a common phenomena within EP that the best polish occurs at voltage levels producing what is known as the current limiting plateau [FIGURE 5], (Datta et al., 1992). In order to find the voltage range of the current limiting plateau, a series of voltage ramping experiments was performed in each of the experiment setups [FIG - current limiting plateau graph]. Following this, when or if an ideal voltage level was found within the current limiting plateau, experiments would be performed to test factors believed strongly affect the response(s). Lastly, the response(s) would be measured and the results analyzed. The intention of repeating the initial current limiting plateau experiments in each of the experiment setups was to both ensure that the innate experiment setup design was not affecting the current limiting plateau and also investigate the ability of each of the experiments to control the temperature of the solution. 
Stir Design Factors Experiments

\begin{tabular}{|c|c|c|}
\hline $\begin{array}{l}4 \text { Levels } \\
\text { Factor } 1\end{array}$ & $\begin{array}{l}3 \text { Levels } \\
\text { Factor } 2\end{array}$ & \\
\hline Time & Distance & Sample \\
\hline Very Short & Small & 1 \\
\hline Very Short & Med & 2 \\
\hline Very Short & Large & 3 \\
\hline Short & Small & 4 \\
\hline Short & Med & 5 \\
\hline Short & Large & 6 \\
\hline Med & Small & 7 \\
\hline Med & Med & 8 \\
\hline Med & Large & 9 \\
\hline Long & Small & 10 \\
\hline Long & Med & 11 \\
\hline Long & Large & 12 \\
\hline
\end{tabular}

Time (s)

\begin{tabular}{|c|c|}
\hline Very Short & 60 \\
\hline Short & 300 \\
\hline Med & 600 \\
\hline Long & 1200 \\
\hline
\end{tabular}

Distance $(\mathrm{mm})$

\begin{tabular}{|c|c|}
\hline Small & 5 \\
\hline Med & 7.5 \\
\hline Large & 10 \\
\hline
\end{tabular}

Flow Design Factors Experiments

\begin{tabular}{|c|c|c|c|}
\hline $\begin{array}{l}2 \text { Levels } \\
\text { Factor } 1\end{array}$ & $\begin{array}{l}2 \text { Levels } \\
\text { Factor } 2\end{array}$ & $\begin{array}{l}3 \text { Levels } \\
\text { Factor } 3\end{array}$ & \\
\hline Temp & Volts & Time & Sample \\
\hline High & Low & Long & 1 \\
\hline High & Low & Med & 2 \\
\hline High & Low & Short & 3 \\
\hline High & High & Long & 4 \\
\hline High & High & Med & 5 \\
\hline High & High & Short & 6 \\
\hline Low & Low & Long & 7 \\
\hline Low & Low & Med & 8 \\
\hline Low & Low & Short & 9 \\
\hline Low & High & Long & 10 \\
\hline Low & High & Med & 11 \\
\hline Low & High & Short & 12 \\
\hline
\end{tabular}

Temp (F)

\begin{tabular}{|c|c|}
\hline High & 100 \\
\hline Low & 85 \\
\hline
\end{tabular}

\section{Volts (V)}

\begin{tabular}{|c|c|}
\hline High & 80 \\
\hline Low & 60 \\
\hline
\end{tabular}

Time (s)

\begin{tabular}{|c|c|}
\hline Low & 300 \\
\hline Med & 600 \\
\hline High & 1200 \\
\hline
\end{tabular}

FIGURE 26 - Experiment designs for both Stir Design and Flow Design experiments.

Both experiment setups included a multiple number of finite level factors.

Experiment designs measured linear, non-binary responses implementing multiple finite level factors. Chosen responses included surface roughness, measured via an Ra value, and sample weight loss as these responses give insight into changes occurring to part surface finish during EP. Factors used included time, distance, temperature and 
voltage. A minimal number of replicates were repeated given the reasonably high cost of solution and time required to run experiments [TABLE 3]. In the Stir Design factors experiments, temperature control was not superlative so temperature was held constant. Given that the focus in these experiments was gauging the affect that time and distance had on polish ( $\mathrm{Ra}$ response), voltage was also held constant while these factors were changed in four and three levels respectively [FIGURE 26]. With the improved temperature control made possible in the Flow Design, temperature was added as a factor. In the Flow design factor experiments, the affect of distance was held constant while the effects of changing temp, volts and time were inspected over two, two and three levels respectively [FIGURE 26].

The factor level values for time in the Stir Design and Flow Design factors experiments were set to values less than 15 minutes, as this was the max value recommended. In the Flow Design factors experiments, the temperature factor levels were set at $85 \mathrm{~F}$ and $100 \mathrm{~F}$ and the voltage factor levels were set to $60 \mathrm{~V}$ and $80 \mathrm{~V}$ given that these ranges corresponded to existing values within literature (Tajima et al., 2008). While this work focused on an uncommon application of the electropolishing of AM Titanium parts, traditional approaches were followed in an attempt to replicate existing successful results with the course surface AM samples. The distance factor levels were set following the assumption that minimizing distance equates to better polish (Sautebin and Landolt, 1982), but also keeping in mind that reasonable space would be needed between the sample and cathode to easily assemble, dissemble and operate the experiment. 


\section{EXPERIMENTAL PROCEDURE}

Experiments were run carefully in order to minimize any source of unintended variation. Experiment preparation and cleaning were performed in a methodical and repeatable fashion.

TABLE 3 - Electrolytic solution calculation for both composition percentages and cost.

\section{Electrolytic Solution Calculation}

\begin{tabular}{|c|c|c|c|c|c|c|c|c|c|}
\hline & & Composition & $\begin{array}{l}\text { Amount } \\
(\mathrm{mL})(\mathrm{g})\end{array}$ & $\begin{array}{c}\text { Total } \\
\text { Amount }(\mathrm{mL})\end{array}$ & $\begin{array}{c}\text { Container } \\
\text { Cost }\end{array}$ & $\begin{array}{c}\text { Container } \\
\text { Size }(\mathrm{mL} / \mathrm{g})\end{array}$ & $\$ / \mathrm{mL}$ or $\mathrm{g}$ & \$/Amount & $\begin{array}{c}\text { Total } \\
\text { Cost/Total } \\
\text { Amt (\$) }\end{array}$ \\
\hline \multirow{2}{*}{$\begin{array}{c}\text { \% of } \\
\text { Solution }\end{array}$} & $70 \%$ & ethyl & 700 & \multirow{4}{*}{1000} & 80 & 1000 & 0.08 & 56 & \multirow{4}{*}{96.07} \\
\hline & $30 \%$ & isopropyl & 300 & & 20 & 1000 & 0.02 & 6 & \\
\hline \multirow{2}{*}{$\begin{array}{l}\text { Parts (g) } \\
\text { per Liter }\end{array}$} & 60 & Alcl3 & 60 & & 147 & 1000 & 0.147 & 8.82 & \\
\hline & 250 & Zncl2 & 250 & & 101 & 1000 & 0.101 & 25.25 & \\
\hline
\end{tabular}

The electrolyte mixture used was a non-aqueous, alcohol-based electrolyte found in literature known to polish Ti6Al4V (Tajima et al., 2008). The solution consists of the above compositions in the following amounts. Of the total volume of solution, the liquid alcohol base of Ethyl Alcohol makes up 70\% and Isopropyl Alcohol makes up 30\%. In grams per liter of solution, anhydrous Aluminum Chloride, AlCl3, makes up $60 \mathrm{~g} / \mathrm{L}$ and anhydrous Zinc Chloride makes up $250 \mathrm{~g} / \mathrm{L}$. Solution mixing was performed under a chemical hood as the reaction occurring during mixing produces fumes. Mixing of the solution is done slowly over approximately $1 \mathrm{hr} / \mathrm{L}$, the reason for this being the cooling time needed to counteract the exothermic nature of the mixing reaction. Solution cost is 
$\$ 96 / \mathrm{L}$, or approximately $\$ 100 / \mathrm{L}$. For each experiment, a solution volume of $200 \mathrm{ml}$ to 400ml was used.

The use of an alcohol-based electrolyte greatly widens the applicability of EP to AM Ti6Al4V. To begin with, using typical strong acids to perform EP would only further complicate the design process, as much more stringent safety guidelines would be required. Apart from safety, design complexity, organization complexity and cost would increase as well. Recalling the Integrated System Layout above, the some 21 lines connecting the experiment components would either need to be lengthened such that they could rest outside of a hood, or compacted such that the entire experiment could take place under a chemical hood, and each piece of equipment made well protected from the electrolyte. Furthermore, if more practically implementable electrolytes exist than strong acids, then the improvement of EP methods using these electrolytes adds long-term value to the overall usefulness of using EP to polish Ti6Al4V.

Temperature control was a major focus during EP. Preliminary experiments showed that the reaction was strongly exothermic, rising quickly in temperature and requiring careful monitoring if temperature was to be managed properly. In the Stir Design, the beaker containing the solution was set in a tray that was filled with ice. As the experiment proceeded, temperature was watched closely and ice was added accordingly in order to minimize temperature drift. Automated commercial temperature control units do exist, but were out of budget. Homemade solutions could have been implemented, but would have required far more time than could have been devoted to one aspect of the work. With the redesign of the solution cooling method in the Flow Design, temperature control 
was improved by sending the solution through a liquid cooled condenser. This meant that solution temperature could be reduced more rapidly. Similarly, as in the Stir Design, temperature was monitored closely, although less ice was required as the cooling/heating loop featured a tap water cooling source. Instead of adding ice to a tray, ice was added to the water bath in the cooling/heating loop. In both cases, water from melted ice was drained during the experiment runs.

Cleaning procedures used following experiments were meant to be efficient as well as thorough. As per the design of the experiment setups, minimal breakdown was required to perform a proper cleaning and all surfaces were easily cleanable. In the Stir Design experiments the entire volume of the solution rested within a glass beaker, meaning that the part support only needed to be lifted from the beaker for cleaning. Following experiments, the used electrolyte was disposed into a waste container and residue was wiped out. The beaker was cleaned using a small quantity of Isopropyl, rinsed with water and dried. The Flow Design cleanup was not as straightforward as the volume of the solution rested within the tubing of the solution circulation loop, the condenser and the polishing chamber. While no disassembly was required, more time was required to ensure that the solution circulation loop was free of solution or cleaning liquid. With the peristaltic pump off, used electrolyte was poured out from the polishing chamber into a waste container. The peristaltic pump would then be turned on and off momentarily while remaining solution was periodically poured out as it reentered the polishing chamber. After the solution was pour out, residue was removed by filling the solution circulation loop with a mixture of water and Isopropyl and circulating the 
mixture via the peristaltic pump. The same procedure as with the solution was repeated. After running the alcohol, water mixture for a minute or two, the mixture was poured out. The loop was then filled again with a fresh alcohol, water mixture and the rinse procedure was repeated until any evidence of the residue had been removed from the loop. Lastly, after most of the final rinse mixture was poured out, a pressurized air line was attached to the solution circulation loop and air was sent through the loop for a number of minutes until no remaining liquid remained within the loop. A high concentration of alcohol in the final rinse ensured that the interior of the loop was able to be made very dry by the compressed air drying given the good evaporation of the alcohol. This method of alcohol cleaning and drying is recommended in literature (Tajima et al., 2008). Maintenance other than cleaning included periodic sanding of metal components holding samples and cathode strips.

After certain experiments, samples were measured to estimate the percent mass lost during polish. The average weight of a small batch of reference samples is set as the reference weight. For any given sample, there is an estimated ideal loss of material that would occur during polishing. Although this amount is not immediately necessary towards completing experiments, this information will be very valuable in future understanding of designing AM parts with EP post processing in mind. By monitoring the mass lost during experiments, the impact of set parameters on mass loss can be better understood.

The primary metric used to measure the effectiveness of the polishing was through the use of a profilometer. The profilometer used was a Dektak 8 capable of measuring 0.1 
- 10nm of surface profiles. The profilometer returned an Ra value representing the average deviation from the mean of surface height, rather the average flatness of a profile taking into account peaks and valleys. Depending on equipment availability, single or multiple scan tracks were performed on each sample. 


\section{RESULTS AND DISCUSSION}

A search for the current limiting plateau with the given solution, Ti6Al4V combination was performed by ramping voltage over time and comparing it to the resultant amperage provided by the power supply. The current, potential curves yielded the following results.

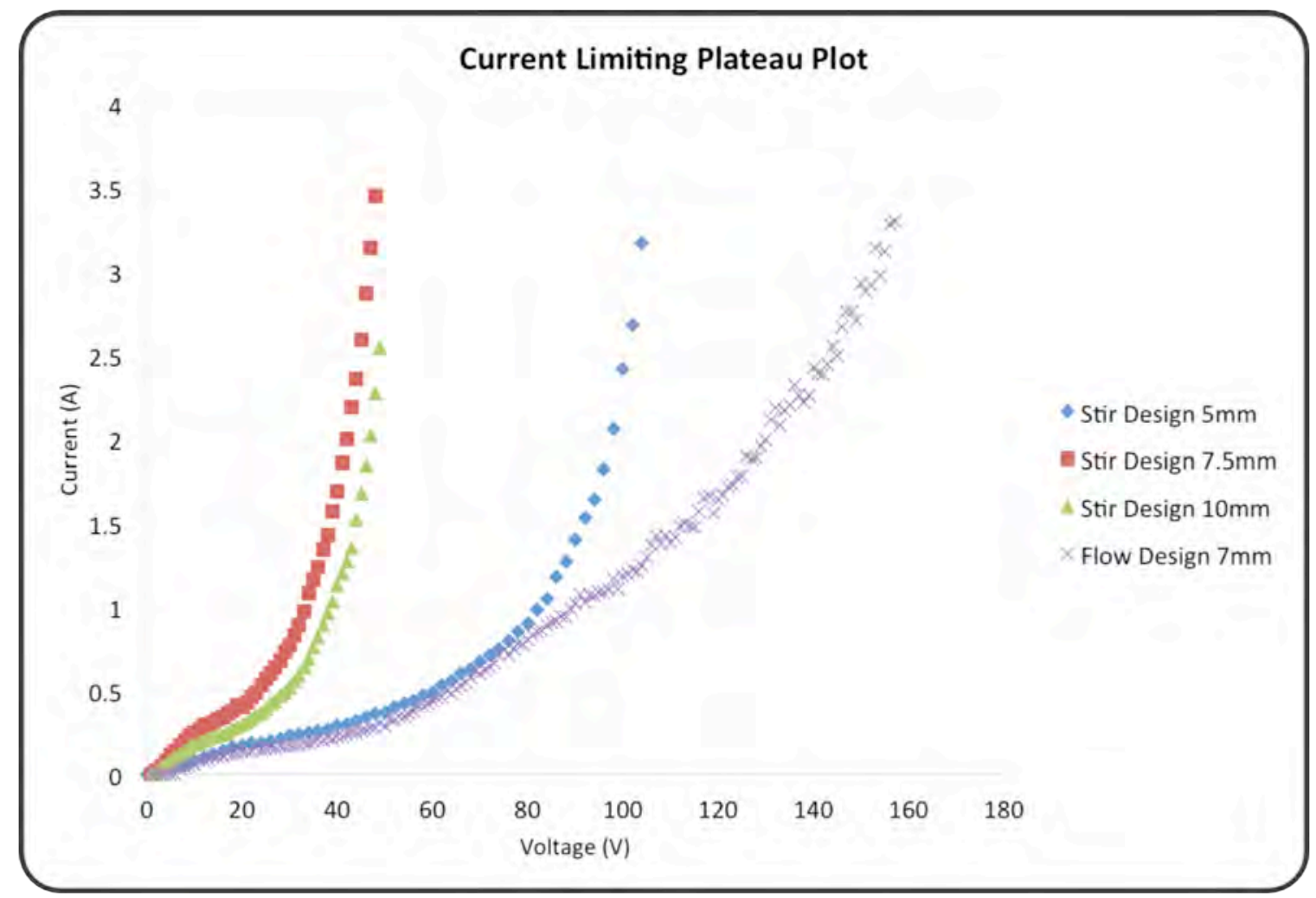

FIGURE 27 - Current/potential plot of voltage ramping experiments designed to find a current limiting plateau for Titanium as well as provide insight into the experiment design setups. 
Voltage ramping experiments were performed in both the Stir Design and Flow Design to make an attempt at determining a current limiting plateau and, if so, whether there might be any discernable differences between the experiment setups. However, at least within the given parameters, it was found that no apparent current limiting plateau existed. This agrees with literature indicating that under similar circumstances, current/voltage combinations, there is no immediately apparent current limiting plateau for Titanium. Nevertheless, polishing had been performed successfully on Titanium above 50 Volts, so this was the region of focus during this work (Tajima et al., 2008).

In a typical current/potential curve featuring a current limiting plateau (such as the conceptual plot above [FIGURE 5]), the onset of the plateau indicates that the electrolytic cell has surpassed what is known as the decomposition potential, the minimum potential difference for electrolysis to occur in an electrolytic cell (Perez, 2004). Recall that an electrolytic cell is the inverse of a galvanic cell [FIGURE 2]. In a galvanic cell a spontaneous chemical reaction occurs within the electrolyte. In an electrolytic cell there is no spontaneous chemical reaction occurring in the electrolyte, however, with sufficient potential, the decomposition potential, a chemical reaction will occur. With no exhibited current limiting plateau, the decomposition potential will need to be tested for following experimental results, measuring the resultant polish quality.

These limited results point to a few promising outcomes. From an operational standpoint, the wider the range of potentials available for testing, the more efficient the use of the power supply as well as latitude for experiments. With a more leveled Wattage $(\mathrm{W}=\mathrm{VI})$ distribution, with wattage being more evenly distributed rather than concentrated 
more strongly within amperage, the performance of the power supply is used most efficiently. A constant power supply, such as the PSW 160-14.4, is wattage limited, with more expensive models offering higher wattages. The PSW 160-14.4, for example, can produce a maximum amperage/voltage combination less than or equal to $700 \mathrm{~W}$. If either the amperage or voltage rises too quickly, as in the three leftmost curves [FIGURE 27], then the corresponding amperage or voltage will be more rapidly limited. This being said, the range of voltages is broadened for which ideal polishing can be tested experimentally. The three leftmost curves in FIGURE 27, corresponding to the Stir Design, indicate that within the Stir Design, experimentation must be limited to some $40 \mathrm{~V}$ for distances larger than $5 \mathrm{~mm}$ and less than $100 \mathrm{~V}$ for distances less than $5 \mathrm{~mm}$. The results of the current limiting plateau experiments seem to indicate that, in the Flow Design, the voltage limitation is extended to beyond the voltage limit of the PSW 160-14.4 power supply. This may perhaps be due in part to the improved solution flow and temperature control of the Flow Design. With these two improvements, cooled solution is brought more rapidly to the part surface, which may minimize localized overheating effects on the part surface.

The difference in performance of the Flow Design allow the EP to be performed at a higher potential for a given current density, meaning that EP can be performed at higher required potential levels and current levels concurrently. If potential levels are too low, ion transport is too insubstantial to encourage surface film growth, and the decomposition potential is not reached (Hoar, Mears, and Rothwell, 1965). Likewise, extending the potential curve to the right also lowers the required current density for a given voltage. Looking at $40 \mathrm{~V}$, for example, the differing levels of required current densities can be 
observed. If amperage is too low, the limiting current may not be reached. It is at the limiting current that the current distribution is mass transport limited by the distribution of the surface film (Sautebin and Landolt, 1982). Bearing in mind that current concentration distribution decides localized leveling rates, as determined by the surface film, the control of the limiting current is necessary for controlling the key mechanism present in EP, the surface film, enabling both leveling and anodic brightening. Below the limiting current, the current distribution is limited by both mass transport and potential distribution, or rather the distance between the anode and the cathode (Landolt, 1987). By reaching the limiting current, the impact of the distance between the anodic sample and cathode is reduced, an important factor in terms of future developments. In the event of polishing varying complex shapes of Ti6Al4V AM parts in future research, it is unlikely that every surface feature can be made equidistant from the cathode during polishing, meaning that reducing the strength of the factor of distance would be of great interest.

The results of FIGURE 27 seem to indicate that changing distance impacts the potential/current distribution within a given setup. Generally, in the Stir Design experiment, it appears that reducing the distance from $10 \mathrm{~mm}$ and $7.5 \mathrm{~mm}$ to $5 \mathrm{~mm}$ creates a more leveled potential/current distribution. Inspecting the Flow Design curve, it is possible that the performance differences within the Flow Design lessened the impact of the distance between the anode and cathode. The Flow Design exhibited a more leveled potential/current curve at a $7 \mathrm{~mm}$ distance than the Stir Design $5 \mathrm{~mm}$ distance [FIGURE 27]. With the limiting current for Titanium expected to be within the range of less than 1 A/cm^2 (Tajima et al., 2008, Hoar, Mears, and Rothwell, 1965), and viewing the Flow 
Design curve on FIGURE 27, it appears likely that the Flow Design can accommodate for testing voltages past the max wattage of the PSW 160-14.4 power supply. Although not conclusively, the voltage ramping, current limiting plateau experiments give some sense of the ability of the experiment design setups, and also minor insight into the effect temperature, distance and even solution flow might have upon accommodating both the decomposition potential and limiting current.

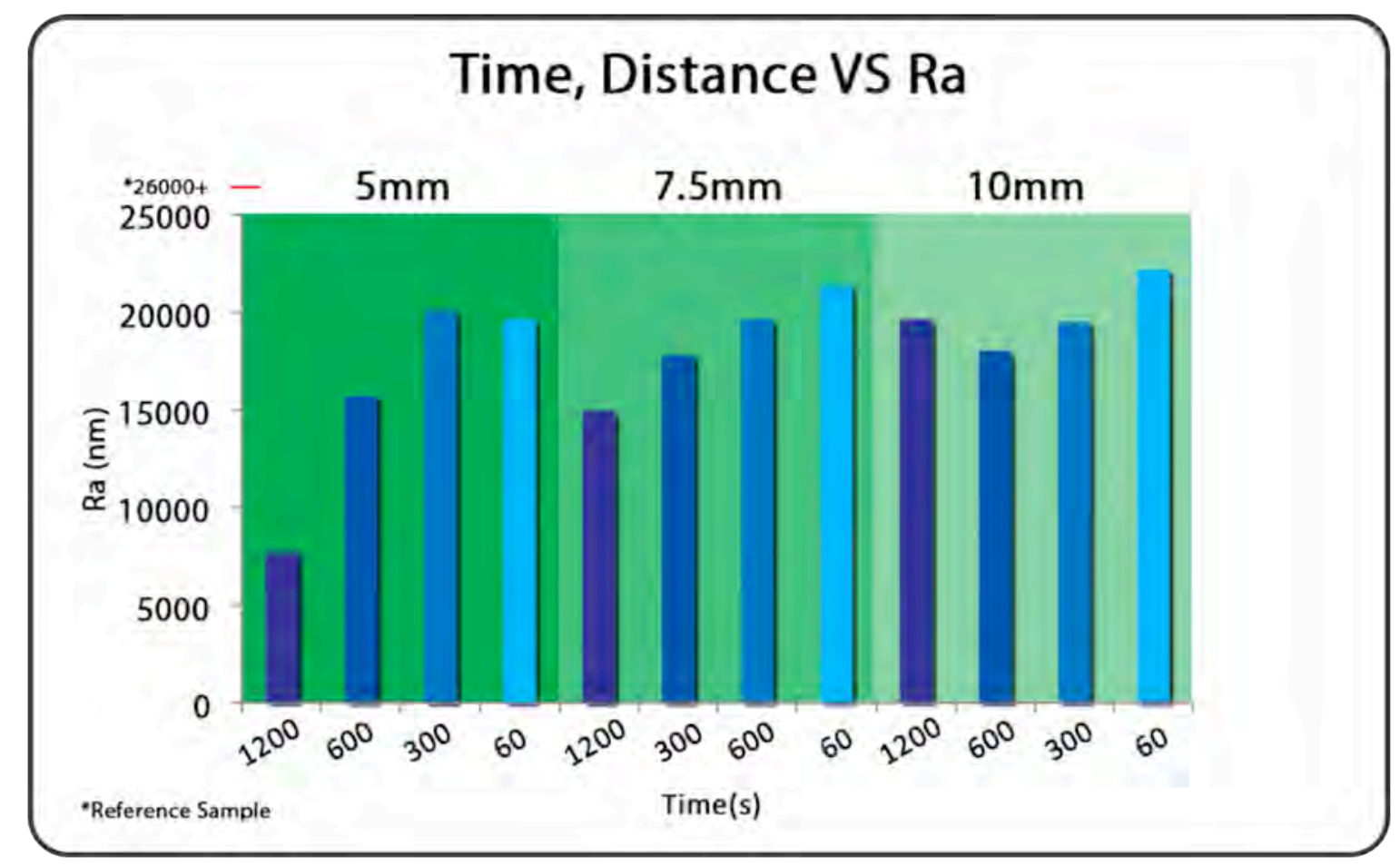

FIGURE 28 - Time, Distance VS Ra plot comparing the impact of differing polish times and inter anode/cathode distances at constant temperature and voltage. Bar colors correspond to polish time.

Experiments were conducted within the Stir Design to test the interaction of polish time and inter anode/cathode distance factors with the Ra response [FIGURE 28]. 
Generally, two trends seem to appear. Firstly, it appears that overall shorter inter anode/cathode distances improve polish and secondly, it is likely that increased time may improve polish as well. This may be the case, within these limited results, given that the best result contains both the shortest distance and longest time while the worst result contains both the largest distance and shortest time. Despite the narrow scope of the number of samples tested, the results agree with similar results in literature, that profile amplitude will decay continually over time (Landolt, 1987, Wagner, 1954) and that reduction in inter electrode distance improves polish (Landolt, 1987). 


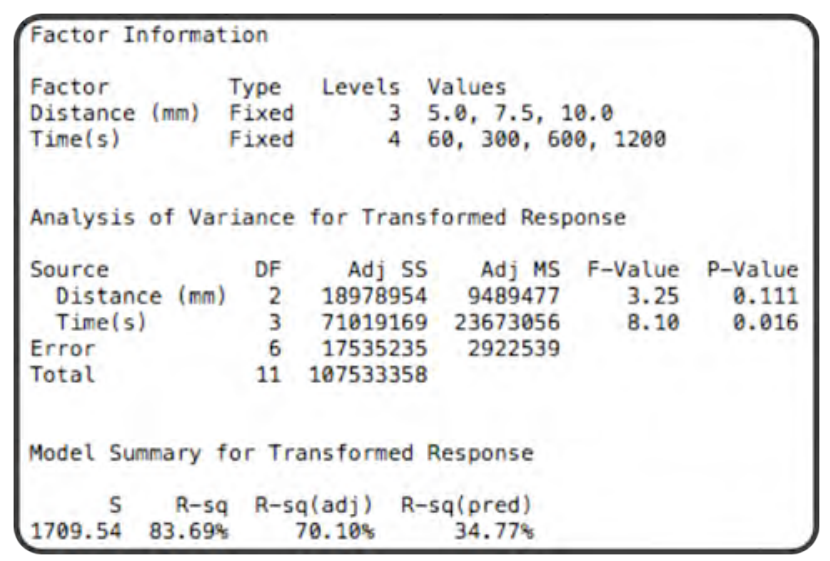

FIGURE 30 - Stir Design factors experiments ANOVA.

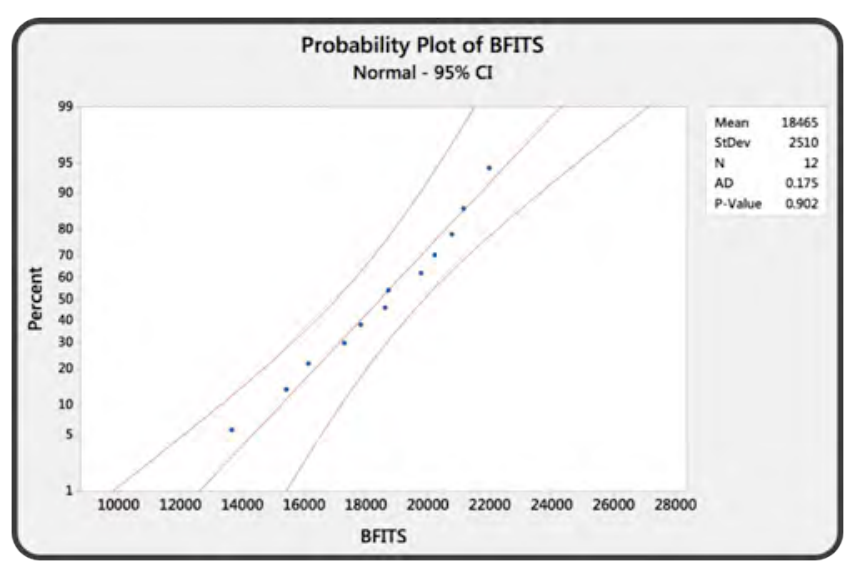

FIGURE 29 - Probability plot of Stir Design factors experiments Box-Cox transformed responses.

After performing a residuals analysis in Minitab, it was determined that the Stir Design experiment responses were not normally distributed. After attempting a number of transformations and given that none of the responses were less than or equal to zero, a Box-Cox transformation, set at $\lambda=4$, was found to perform as a decent transformation on the responses. An ANOVA was performed on the data [FIGURE 29] with the CI set at 95\% and $\alpha=0.05$. Inspecting the ANOVA P-Values, the ANOVA suggests that Time 
significantly affects $\mathrm{Ra}$, while also indicating that Distance does so to a lesser extent. Following what was suggested by the current limiting plateau experiments this seems sensible, given that, if the limiting current was reached during EP, the effect of Distance on the Ra value would have been minimized. The Box-Cox transformation performed fairly, with a decent R-Squared value and a probability plot P-Value of 0.9 [FIGURE 29].

\begin{tabular}{|c|c|c|c|}
\hline $\begin{array}{l}\text { Distance } \\
(\mathrm{mm})\end{array}$ & $\mathrm{N}$ & Mean & Grouping \\
\hline 10.0 & 4 & 20027.3 & A \\
\hline 7.5 & 4 & 18901.3 & A \\
\hline 5.0 & 4 & 17540.1 & A \\
\hline Time(s) & $N$ & Mean & Grouping \\
\hline 60 & 3 & 21155.5 & A \\
\hline 300 & 3 & 19779.6 & A \\
\hline 600 & 3 & 17301.0 & B \\
\hline 1200 & 3 & 16143.7 & B \\
\hline
\end{tabular}

FIGURE 31 - Stir Design experiments pairwise Tukey test.

Looking more into interactions between factors, pairwise Tukey tests were applied to both the Distance and Time factors [FIGURE 31]. Similarly to the ANOVA, the Tukey test indicated that Distance was a factor in lowering the Ra response, but not as strongly as longer times. 


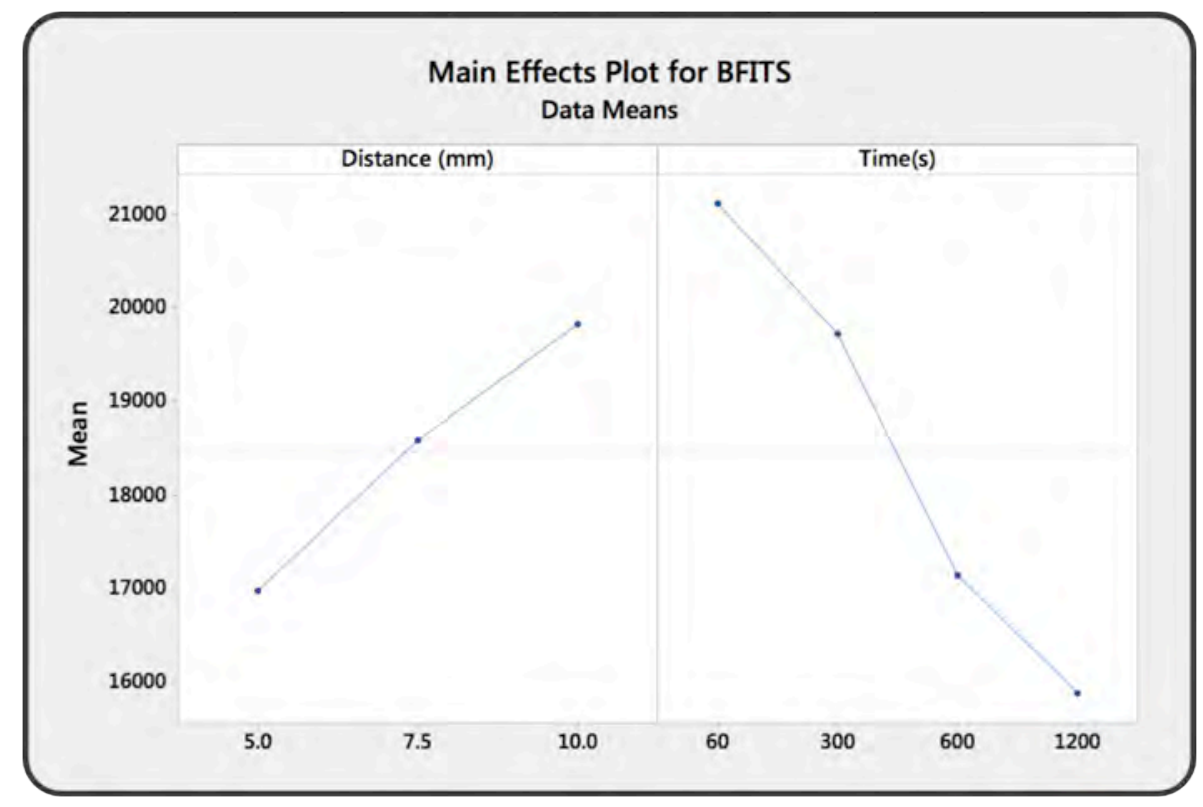

FIGUER 32 - Main effects plot of Box-Cox transformed Stir Design experiment responses.

A main effects plot of the Box-Cox transformed Stir Design responses was performed. Keeping in mind that strong conclusions cannot be drawn from the limited data points, generally the main effects plot seemed to show that Time was again a stronger factor, as shown more steeply on the plot than distance. Also, the impact between longer times versus shorter times appeared to be more dramatic than the impact within shorter times and longer times [FIGUER 32]. 


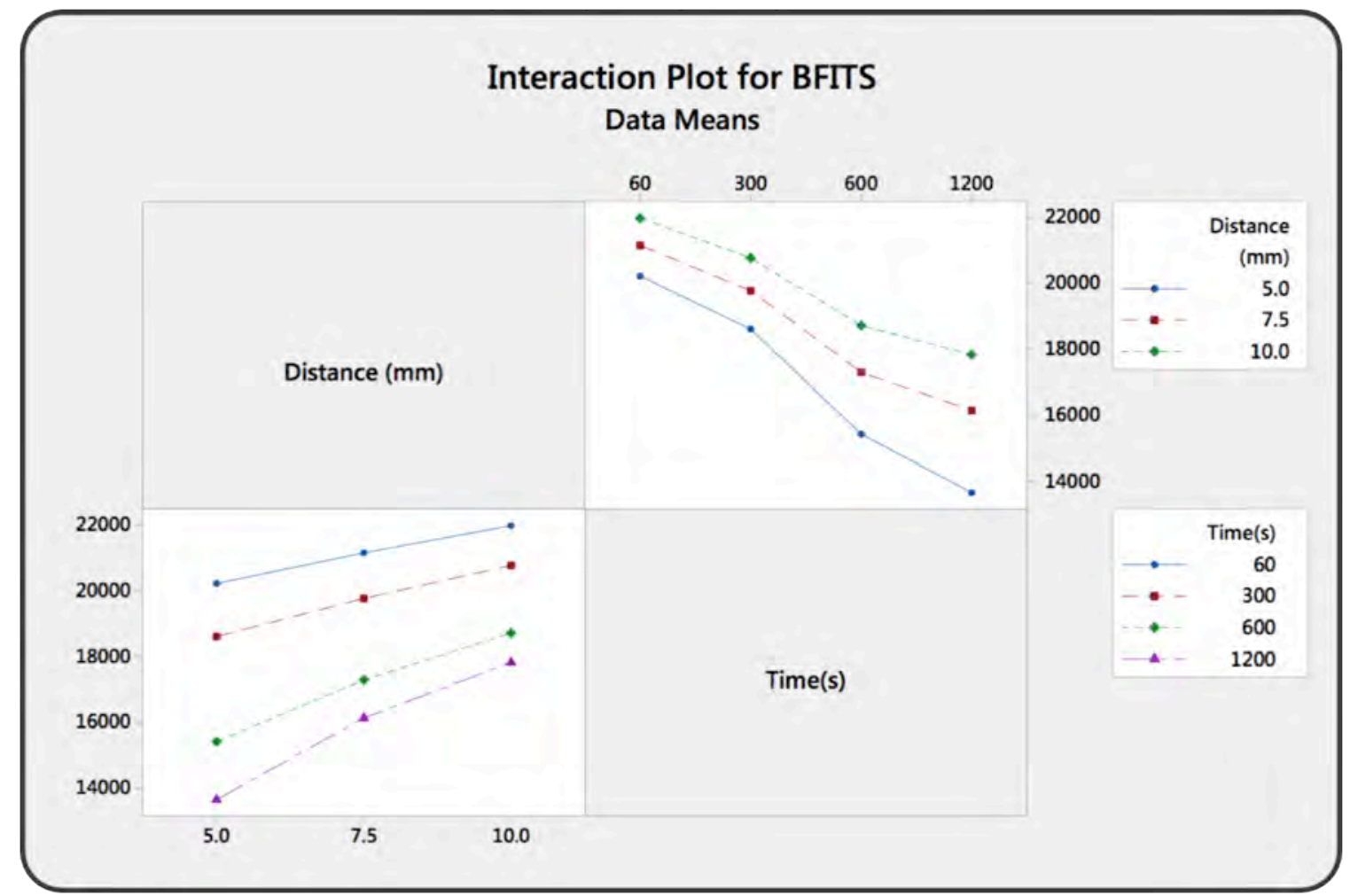

FIGURE 33 - Interaction plot of Box-Cox transformed Stir Design experiment responses

The top right interactions plot of the Box-Cox transformed Stir Design responses seem to indicate that, while both Distance and Time affect Ra, the factors are parallel and may not rely on one another. It is interesting to note that the steepness of the $\mathrm{Ra}$ improvement increases with lessening distance, proposing that perhaps, while not as strong an effect as Time under these parameters, Distance might play a role in lessening the $\mathrm{Ra}$ response as well. The bottom left interactions plot shows that lessening distance has an effect in lessening the Ra response as shown by the steepening curves as Time increases and distance decreases [FIGURE 33]. 
While Time and Distance may affect the Ra response at a constant Temperature and Voltage, the affect of Time is shown to be more statistically significant within these limited experiments, although nevertheless important. As previously considered, the primary focus of future work is to reduce the reliance on inter electrode distance towards providing good Ra values as this may not be possible in future work. The Stir Design factors experiments shed some light on the strength of the Distance factor in the EP process.

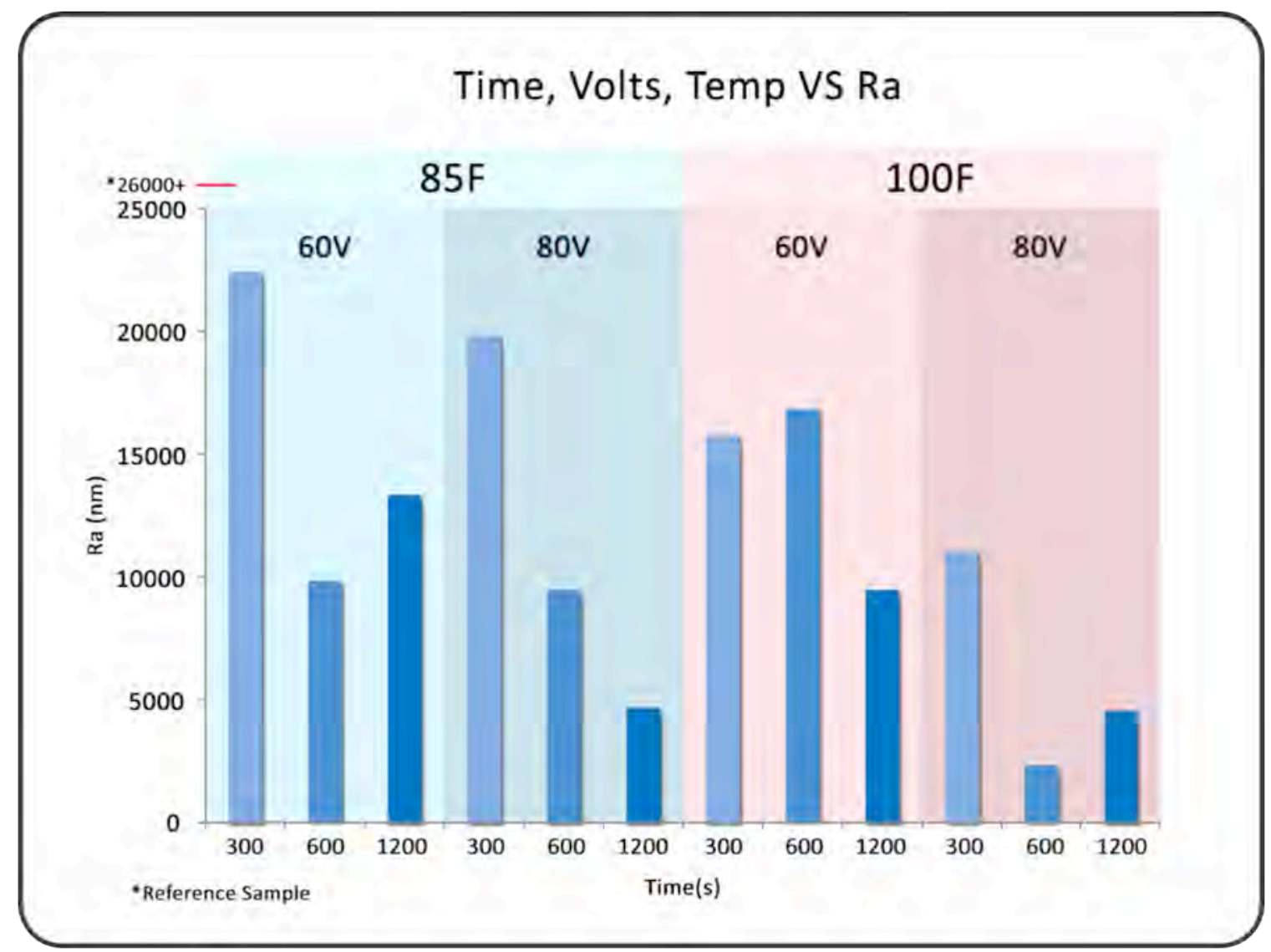

FIGURE 34 - Time, Volts, Temp VS Ra plot comparing the impact of differing time, volts and temp at a constant distance. Bar colors correspond to polish time. 
In the Flow Design experiments, Distance is held constant while Temperature, Time and Voltage are varied at multiple finite levels [FIGURE 34]. Generally, it appears that higher Temperature and Voltage combinations work best together, while lower Temperature and Voltage combinations work less well. The most predictable of the subsets seen above is the $85 \mathrm{~F}-80 \mathrm{~V}$ subset, most closely following the general trend, a linear trend of lowered Ra responses with increased Time and Voltage. The 85F-80V region seems to suggest that lower temperatures, $85 \mathrm{~F}$ versus $100 \mathrm{~F}$, might also be an avenue for lowering Ra values. It is possible that in maintaining a lower solution temperature, the solution itself might act as a heat sink to dissipate localized temperature surges propagating from the reaction occurring at the part surface (Cleric, Datta, and Landolt, 1984). Providing a sufficiently strong heat sink for the surface temperature on the sample during EP can help to homogenize the rate of the reaction over the part surface by limiting the influence of localized temperature spikes (Cleric, Datta, and Landolt, 1984). This in mind, the inverse may be true within the $100 \mathrm{~F}-80 \mathrm{~V}$ region. Similar to the $85 \mathrm{~F}-80 \mathrm{~V}$ region, the $100 \mathrm{~F}-80 \mathrm{~V}$ differs in factor levels only by temperature, but does not return exactly similar responses. The $100 \mathrm{~F}-80 \mathrm{~V}$ region has a higher temperature, which could lead to high rates of dissolution, but would also have decreased solution induced, sample surface heat dissipation over time, given the higher temperature. This is possibly the case within the $100 \mathrm{~F}-80 \mathrm{~V}$ region as it appears that the performance of the combination perhaps begin dulling the part surface past a certain time, sometime between $600 \mathrm{~s}$ and $1200 \mathrm{~s}$. Returning to the lower temperature region of the plot, the $85 \mathrm{~F}$, $60 \mathrm{~V}$ region, a similar effect may be in action. At lower temperatures and lower voltages, 
this may be due to the fact that the dissolution proceeds too slowly overtime as caused by either lower temperature or lower voltage, again having a net dulling effect on the part sometime past $600 \mathrm{~s}$. It is only in the higher volt, lower temp $(80 \mathrm{~V}, 85 \mathrm{~F})$ and higher temp, lower volt $(100 \mathrm{~F}, 60 \mathrm{~V})$ regions that the polishing behaved predictably past $600 \mathrm{~s}$. This could be reasonable given that in each of these scenarios the Temperature and Voltage might perhaps be acting complimentarily to one another as opposed to working against one another, either both trying to move the reaction along too quickly or move the reaction along too slowly.

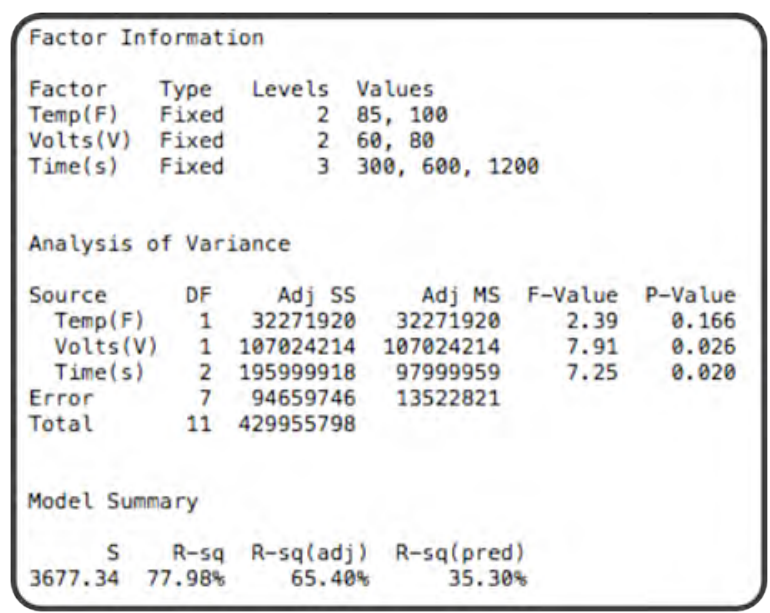

FIGURE 35 - Flow Design factors experiments ANOVA. 


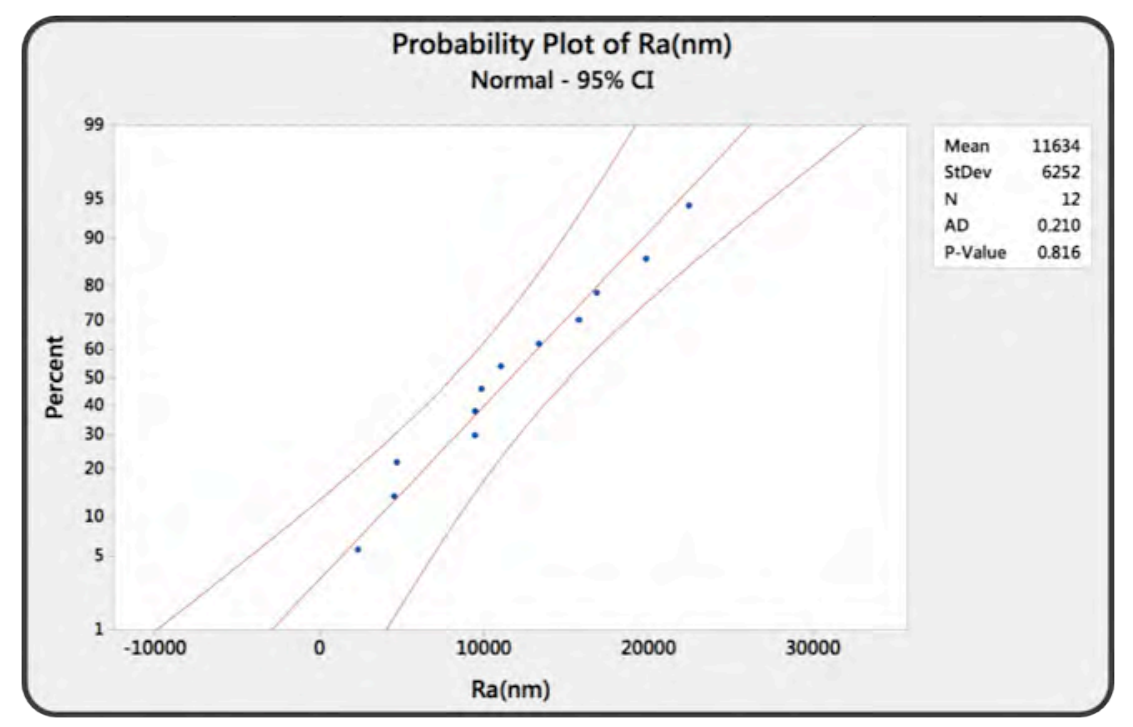

FIGURE 36 - Probability plot of Stir Design factors experiments Box-Cox transformed responses.

A residuals analysis in Minitab revealed that the Flow Design experiment response values were reasonably normally distributed with a probability plot P-Value of 0.82 [FIGURE 36]. An ANOVA analysis with a $\mathrm{CI}$ set at $95 \%$ and $\alpha=0.05$, returned P-Values suggesting that both Voltage and Time affect the Ra response more strongly than Temperature [FIGURE 35]. The fit of the Ra responses to the ANOVA held an independently fair R-Squared value.

\begin{tabular}{|lrrll|}
\hline Temp (F) & N & Mean & Grouping \\
85 & 6 & 13273.7 & A \\
100 & 6 & 9993.8 & A \\
& & & & \\
Volts (V) & $\mathrm{N}$ & Mean & Grouping \\
60 & 6 & 14620.2 & A & \\
80 & 6 & 8647.3 & & B \\
& & & & \\
Time(s) & $\mathrm{N}$ & Mean & Grouping \\
300 & 4 & 17272.8 & A & \\
600 & 4 & 9621.3 & A & B \\
1200 & 4 & 8007.2 & & B \\
\hline
\end{tabular}

FIGURE 37 - Flow Design experiments pairwise Tukey test. 
A pairwise Tukey test found a similar result to that in [FIGURE 34]. The longest Time, $1200 \mathrm{~s}$, and higher Voltage, $80 \mathrm{~V}$, appeared to be more significantly affecting the Ra response.

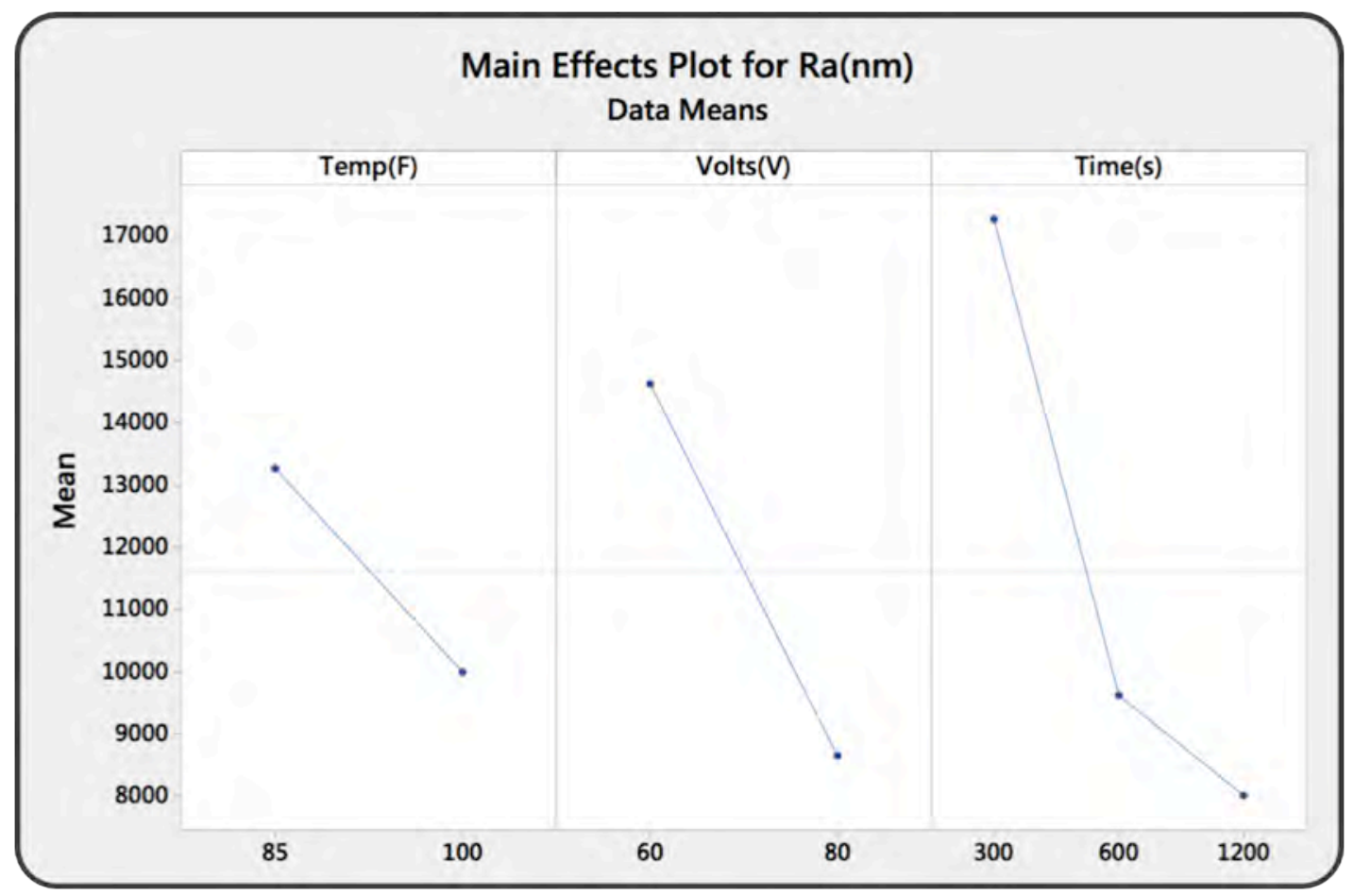

FIGURE 38 - Main effects plot of Flow Design experiment responses

A main effects plot of the Ra response of the Flow Design factors experiments cannot conclusively rank the strength of factors given the limited number of observations, but may give limited insight to such rankings. If there are no major deviations in response between observations, the main effects plot may indicate the strongest, steepest, overall effect being Time, with a gradual decrease in strength proceeding to Volts and Time. Within each of the factors the quality of the response improves as the magnitude of each 
factor is increased. It is interesting to note the reduction in slope in the Time factor. While there are a small number of observations, this may indicate a lessening of the impact of added Time as more time is added to the EP, but more likely may be describing a positive result occurring during EP, that high surface profiles, greatest changes in Ra, are leveled rapidly, followed then by smaller profile features, smallest changes in Ra, being polished more slowly. If the surface film acts as intended, resting more densely in the valleys than on the peaks of the surface profile, then as the difference in height between the surface valleys and peaks diminishes during leveling, so too does the rapidity of the overall dissolution. As the average thickness of the surface film diminishes, the broader the regions current must cover, lowering the overall current density. Also in effect is the solution flow, with the purpose of attempting to ensure the surface film maintains a difference in thickness across the part profile.

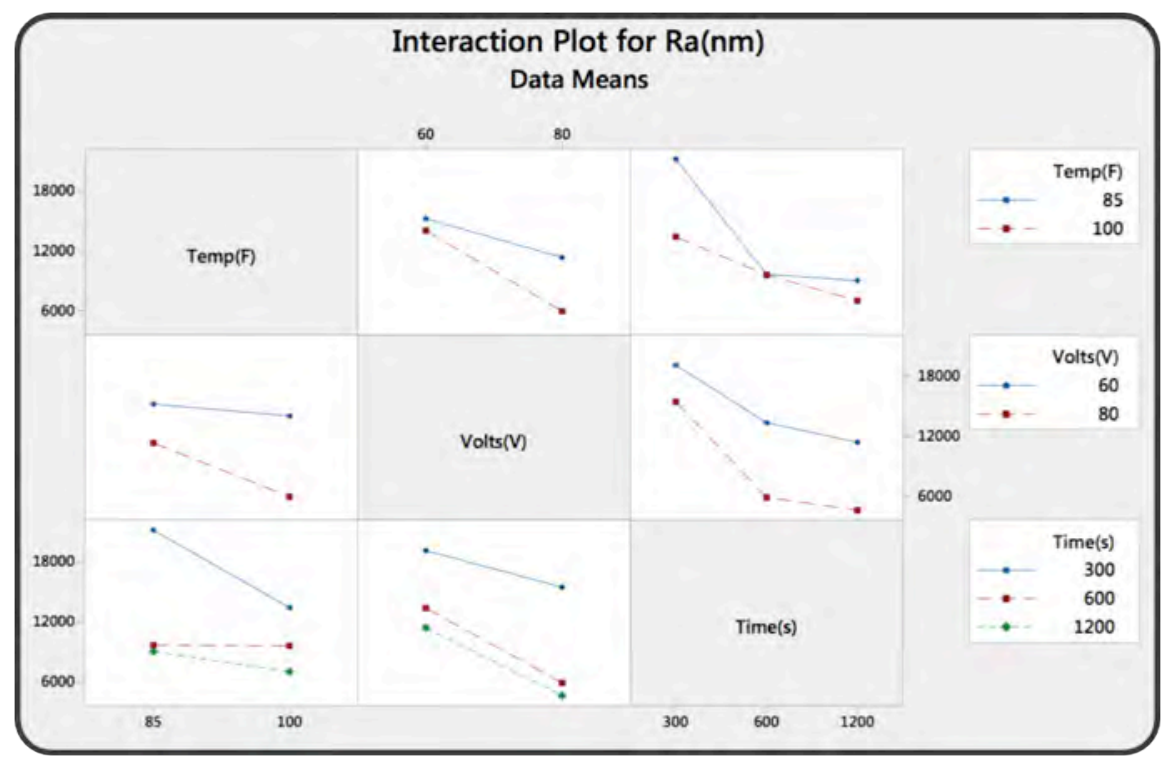

FIGURE 39 - Interaction plot of Flow Design experiment responses. 
The interactions plot may provide additional insight into the specific effect that Temperature and other factors might have on the EP, under the assumption that there are no major deviations between these limited observations. In the top middle plot, it can be seen that, interacting with Voltage, Temperature may be acting as a catalyst towards lowering the response. In the top right plot, Temperature appears that it may be performing initially better at lower Temperatures and then leveling off in performance unless switched to a higher Temperature later in the EP. This result, in conjunction with the right middle plot, suggests that an initially lower Temperature, in conjunction with a higher Voltage is best initially and then perhaps it is best to change later in the EP to a lower Voltage and a higher Temp. Looking at the bottom middle plot, higher Volts appear to improve the response increasingly over longer periods of Time. The impact of Temperature on time, bottom left plot, presents interesting results. This plot seems to indicate that difference in Temperature is an important effect initially, and has little effect in the middle of the process, but then begins to increase in importance much later in the EP. Lastly, in the left middle plot, comparing Temperature and Voltage directly, it can be seen that difference in Temperature appears to depend more greatly the larger the Voltage being applied during polishing. At lower Temperatures, it appears that greater changes in Voltage have less effect. What this may indicate is that lower Temperatures might actually inhibit polishing by limiting the effect of increased Voltage. As Temperature reduces, so too does the rate of the reaction. 


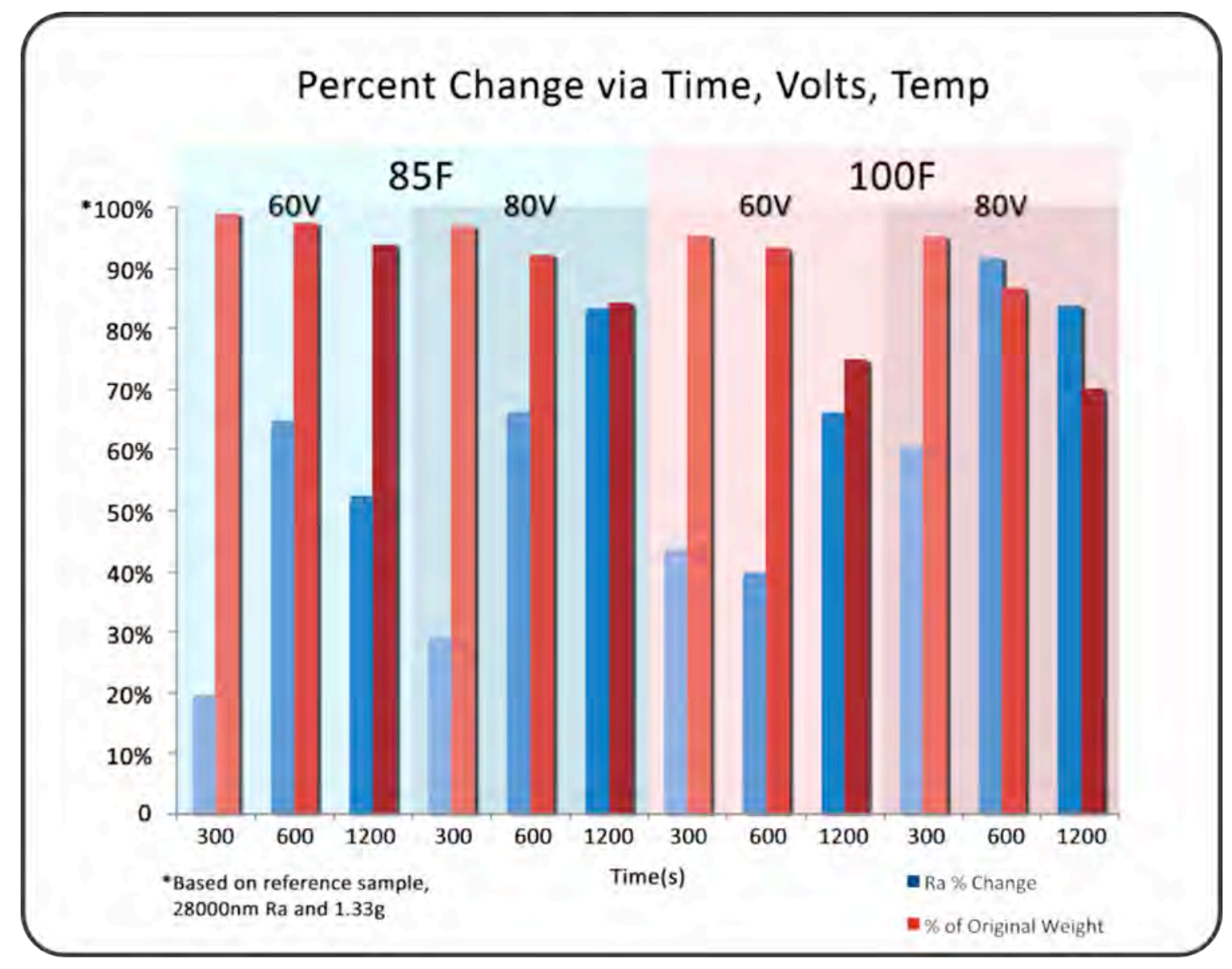

FIGURE 40 - Percent change via Time, Volts and Temp plot comparing percentage of Ra and change from original weight. Bar colors correspond to polish time.

The comparison of weight loss during EP to Ra response improvement ties together previous topics as well as bringing to light another factor that must be considered for successful future work. While the previous plots consider purely the Ra response, the above plot considers how this response is interacting with the associated weight loss incurred during EP [FIGURE 40]. While the above plot cannot conclusively indicate specific differences given the limited number of responses, it can shed light on general, positive trends. In the above plot, columns indicate greater values with positive 
outcomes. Each set of columns is a paired group that when increased towards $100 \%$, aim at achieving both lower Ra values, while concurrently minimizing loss of mass in the process. Assuming that the limited observations provide some general insight, three stand out as having the best correspondence, smallest difference, while also maintaining high magnitudes, $85 \mathrm{~F}-80 \mathrm{~V}-1200 \mathrm{~s}, 100 \mathrm{~F}-60 \mathrm{~V}-1200 \mathrm{~s}$, and $100 \mathrm{~F}-80 \mathrm{~V}-600 \mathrm{~s}$. This is not conclusive, but may indicate that, generally, longer times at either low Voltage and high Temp or high Temp and low Voltage, or moderate times at high Voltage and high Temp may be best. Intuitively this is reasonable as Time and Temp either work complimentarily for longer periods of time or collaboratively for more moderate periods of time. 


\section{CONCLUSION AND FUTURE WORK}

This work was specifically designed to lead into and/or pave the opportunity to further investigate a broad number of factors not approached here. While EP is commonly performed at a set voltage level, modulation of the potential magnitude and polarity has been shown to improve polish and the specialized LabView power supply controls lend to investigating this effect at least in preliminary research. By turning the power source off, time is given for the solution to re-homogenize and cool, and for the surface film to "reset". Reversing the current, essentially temporarily un-plating and unpolishing the cathode and anode respectively, minimized negative impacts of the surface film (Taylor et al., 2013). It is known that changes in solution concentration can change polish quality (Hoar, Mears, and Rothwell, 1965). While changing this concentration in situ will introduce additional challenges, the loop construction of the Flow Design makes the addition of a concentration modifying system more simplified. If study would like to be performed on solution aging, the solution circulation loop also enables easy sampling by tapping into the loop. The effect of part manipulation on polish quality and uniformity can also be more easily studied with the Flow Design. An open top, small polishing chamber, provided for by the circulation of the solution for cooling, creates a manageable platform for testing part manipulation on a small scale. Flow Design 2 is specifically designed to be capable of performing the EP of tensile bars, an important sample needed for future research on the improvement of strength characteristics via EP. Other materials 
such as Inconel can easily be tested in such a setup. The glass and easily replaceable tubing of the solution circuit make it ideal for testing different solutions. Lastly, the effect of temperature on polish can be studied more in depth with the addition of a high quality temperature control unit. The Flow Design is designed such that components are modular, meaning that items such as the cooling/heating pump can be swapped easily.

Surface finish improvement is a necessary performance improvement towards increasing the value of an already valuable AM process, EBM, and AM materials, particularly Ti-6Al-4V (Weller, Kleer, and Piller, 2015). Understanding of the improvement of surface finish in this common metal PBF AM material will provide insight into developing future metal PBF AM parts with a reduced tendency towards failure initiated by poor surface finish. EP is promising given that it may improve surface finish while still providing the design flexibility of AM since it is possible for cavities to be polished, a task very challenging or impossible using machining (Taylor et al., 2013). With the use of a non-aqueous, alcohol based electrolyte, a substantially less toxic electrolyte than typical titanium EP electrolytes, there is an increased ease of use for the process of EP of Ti-6Al-4V (Mathieu, Mathieu, and Landolt, 1978, Tajima et al., 2008, Dobrev, Pham, and Dimov, 2007). This work inspected closely the general and specific challenges associated with the EP of Ti6Al4-V and discovered a number of key performance areas required for future AM, EP research. The EP of AM parts is a complex problem including a broad number of factors to consider, some existing initially, others arising either during the EP process itself or later during continued research. The proper control of the surface film is one such factor. Controlling the surface film is very 
important towards achieving low Ra values, however finer and more accurate controls will yet be required as research in this area continues. Likewise, the impact of temperature and voltage on EP are sometimes mutually detrimental and other times mutually beneficial and improved measurements will be required for better understanding. Lastly, knowledge in this area will need to be fed back into the initial design and manufacture of the AM parts if high quality surface finish of metal PBF AM parts is to be ultimately achieved. 


\section{REFERENCES}

Bhavar, Valmik, Prakash Kattire, Vinaykumar Patil, Shreyans Khot, Kiran Gujar, and Rajkumar Singh. 2015. "A Review on Powder Bed Fusion Technology of Metal Additive Manufacturing." International Conference \& Exhibition on Additive Manufacturing Technologies Bangalore, India.

Cleric, C., M. Datta, and D. Landolt. 1984. "On the Theory of Anodic Levelling: Model Experiments with Triangular Nickel Profiles in Chloride Solution." Electrochemica Acta 29 (10):1477-1486.

Datta, D., L. F. Vega, L.T. Romankiw, and P. Duby. 1992. "Mass Transport Effects During Electropolishing of Iron During Phosphoric-Sulfuric Acids." Electrochemica Acta 37 (13):2469-2475.

Dobrev, T., D. T. Pham, and S. S. Dimov. 2007. "Electro-chemical polishing: a technique for surface improvements after laser milling." International Conference on MultiMaterial Micro Manufacture.

Edwards, P., A. O'Conner, and M. Ramulu. 2013. "Electron Beam Additive Manufacturing of Titanium Components: Properties and Performance." Journal of Manufacturing Science and Engineering 135. doi: 10.1115/1.4025773.

Ford, Sharon L.N. 2014. "Additive Manufacturing Technology: Potential Implications for U.S. Manufacturing Competiveness." Journal of International Commerce and Economics 4.

Gao, Wei, Yunbo Zhang, Devarajan Ramanujan, Karthik Ramani, Yong Chen, Christopher B. Williams, Charlie C.L. Wang, Yung C. Shin, Song Zhang, and Pablo D. Zavattieri. 2015. "The status, challenges, and future of additive manufacturing in engineering." Computer Aided Design 69 (2015):65-89.

Gibson, I., D. W. Rosen, and B. Stucker. 2015. Additive manufacturing technologies : 3D printing, rapid prototyping and direct digital manufacturing. Second edition. ed. New York ; London: Springer.

Halász, Gábor, Balázs Gyüre, Imre M. Jánosi, K. Gábor Szabó, and Tamás Tél. 2007. "Vortex flow gerated by a magnetic stirrer." American Journal of Phyics 75 (12):1092-1098.

Hoar, T.P., D. C. Mears, and G. P. Rothwell. 1965. "The Relationships Between Adnodic Passivity, Brightening and Pitting." Corrosion Science 5:279-289. 
Jadhav, P. V., and D.S. Mankar. 2010. "Effect of Surface Roughness on Fatigue Life of Machined Component of Inconel 718." International Conference on Effect of Surface.

Kakde, Nagnath, Tejas Deshmukh, Akshaykumar Puttewar, and S.V. Lutade. "Advancement in surface finishing by abrasive flow machining:Review." International Journal of Engineering Research and General Science Volume (IJERGS) 2 (6):1044-1048.

King, W. E., A. T. Anderson, R. M. Ferencz, N. E. Hodge, C. Kamath, S. A. Khairallah, and A. M. Rubenchik. 2015. "Laser powder bed fusion additive manufacturing of metals; physics, computational, and materials challenges." AIP Applied Physics Reviews 2 (4).

Kruth, J.-P., M.C. Leu, and T. Nakagawa. 1998. "Progress in Additive Manufacturing and Rapid Prototyping." CIRP Annals - Manufacturing Technology 47 (2):525540. doi: 10.1016/S0007-8506(07)63240-5.

Landolt, D. 1987. "Fundamental Aspects of Electropolishing." Electrochimica Acta 32 (1):1-11.

Loeber, L., S. Boamino, U. Ackelid, S. Sabbadini, P. Epicoco, P. Fino, and J. Eckert. 2011. "Comparison of selective laser and electron beam melted Titanium Aluminides." Solid Freeform symposium (SFF), Austin, TX.

Mani, Mahesh, Brandon Lane, Alkan Donmez, Shaw Feng, Shawn Moylan, and Ronnie Fesperman. 2015. Measurement Science Needs for Real-time Control of Additive Manufacturing Powder Bed Fusion Processes. edited by National Institute of Standards and Technology (U.S.).

Mathieu, J. B., H. J. Mathieu, and D. Landolt. 1978. "Electropolishing of Titanium in Perchloric Acid-Acetic Acid Solution." ElectroChemical Society (ECS): Electrochemical Science and Technology 125 (7):1039-1043.

Perez, Nestor. 2004. Electrochemistry and Corrosion Science. Boston: Kluwer Academic Publishers.

Prinz, Friedrich B., Clinton L. Atwood, Richard F. Aubin, Joseph J. Beaman, Robert L. Brown, Paul S. Fussell, Allan J. Lightman, Emanuel Sachs, Lee E. Weiss, and Michael J. Wozny. 1997. Rapid Prototyping in Europe and Japan. Japanese and World Technology Evaluation Centers (JTEC)/ World Technology and Services (WTEC) Panel. 
Rawal, Suraj, James Brantley, and Nafiz Karabudak. 2014. Additive Manufacturing of Ti-6Al-4V Alloy Components for Spacecraft Applications. NASA Tech Briefs.

Sautebin, R., and D. Landolt. 1982. "Anodic Leveling under Secondary and Tertiary Current Distribution Conditions." Electrochemica Acta 129 (5):946-953.

Tajima, Kiyoshi, Masahisa Hironaka, Ker-Kong Chen, Yuki Nagamatsu, Hiroshi Kakigawa, and Yoshio Kozono. 2008. "Electropolishing of CP Titanium and Its Alloys in an Alcoholic Solution-based Electrolyte." Dental Materials Journal 27 (2):258-265.

Taylor, E. J., M. Inman T. Hall, S. Snyder, and A. Rowe. 2013. "Electropolishing of Niobium SRF Cavities in Low Viscosity Aqeous Electrolytes without Hydrofuouric Acid." SRF 2013, International Conference on RF Superconductivity, Paris, France.

Thomas, Douglas S., and Stanley W. Gilbert. 2014. Costs and Cost Effectiveness of Additive Manufacturing. edited by National Institute of Standards and Technology (U.S.).

V.Wong, Kaufui, and Aldo Hernandez. 2012. "A Review of Additive Manufacturing." International Scholarly Research Network 2012. doi: 10.5402/2012/208760.

Wagner, Carl. 1954. "Contribution to the Theory of Electropolishing." ElectroChemical Society (ECS): Electrochemical Science and Technology 101.

Weller, Christian, Robin Kleer, and Frank T. Piller. 2015. "Economic implications of 3D printing: Market structure models in light of additive manufacturing revisited." International Journal of Production Economics 164 (2015):43-56.

Wu, Tong, Suchana A. Jahan, Praveen Kumaar, Andres Tovar, Hazim El-Mounyri, Jing Zhang, Doug Acheson, Kim Brand, and Razi Namlim. 2015. "A Framework for Optimizing the Design of Injection Molds with Conformal Cooling for Additive Manufacturing." Procedia Manufacturing 1:404-415. doi: 10.1016/j.promfg.2015.09.049. 


\section{APPENDIX II \\ APPOINTMENT OF MEMBERS OF THE EXAMINATION COMMITTEE}

UNIVERSITY OF LOUISVILLE

J. B. SPEED SCHOOL OF ENGINEERING

(Date)

MEMO TO: Academic Affairs Office

J. B. Speed School of Engineering

FROM: $\quad$ (Insert name of Thesis Director, and Home Department)

SUBJECT: Appointment of Members of the Master of Engineering Examination Committee for (Insert name of M.Eng. candidate)

THROUGH: (Insert name of Department Chair)

\section{CONSTITUENCY OF EXAMINATION COMMITTEE}

It is recommended that the following individuals be officially designated as members of the Master of Engineering Examination Committee of subject M.Eng. candidate. Each of these persons has been contacted, and has agreed to serve on the Examination Committee (see page 1 for more detail on constituency of the committee):

(Name, Department)

1.

2. Thesis Director

3. Member

4. Member Member

In addition to the foregoing membership of the Examination Committee, it is requested that the following committee representatives from outside Speed School, each of whom has agreed to serve, be appointed as Members of the Examination Committee:

1. External Member (Name)

(Mailing Address of External Member)

2. (Name) External Member

(Mailing Address of External Member)

II. M.ENG. PROJECT DESCRIPTION

A brief description of the proposed M.Eng. Project is as follows: 


\section{APPENDIX II \\ (continued)}

A tentative title (10 words or less) of the proposed M.Eng. Thesis is:

(Signature of Thesis Director)

\section{III.APPROVAL BY DEPARTMENT CHAIR}

The Thesis Director has conferred with me relative to the investigation, thesis topic and committee membership of the indicated student, and I concur with the recommendations.

(Signature of Department Chair)

General Instructions:

The student in collaboration with the Thesis Director should prepare this form: original to the Department Chair, copy retained by the student, and one copy for the Thesis Director's file.

Full-time students must submit the project description and constituency of the Master of Engineering examination committee according to the specific dates in Appendix I.

Part-time students must submit the project description and constituency of a Master of Engineering examination committee not later than one calendar year prior to the student's expected date of graduation.

Approval form to be distributed by Department Chair to M.Eng. candidate, thesis director, committee members, and Academic Affairs Office. 
APPENDIX III

\section{ORAL EXAMINATION REQUEST}

\section{UNIVERSITY OF LOUISVILLE}

\section{J. B. SPEED SCHOOL OF ENGINEERING}

(Date)

MEMO TO: Academic Affairs Office

FROM: $\quad$ (Insert name of M.Eng. Thesis Director)

SUBJECT: M.Eng. Oral Examination and Thesis Defense for (Name of Student)

1. The oral examination and thesis defense of subject degree candidate will be held on (Day of Week), (Date), at (Time) in Room

No. of (Building).

2. The title of the M.Eng. Thesis is:

(Signature of Thesis Director)

THE STUDENT IS RESPONSIBLE FOR DISTRIBUTION OF THESE COPIES

Copies to: 1) Department Chair

2) Thesis Director

3) Committee Member

4) Committee Member

5) Committee Member

6) Committee Member 


\section{APPENDIX IV}

\section{ORAL EXAMINATION RESULTS}

\section{UNIVERSITY OF LOUISVILLE}

\section{J. B. SPEED SCHOOL OF ENGINEERING}

MEMORANDUM TO:

FROM:

SUBJECT:
Academic Affairs Office (Insert name of Thesis Director)

M.Eng. Oral Examination and Thesis Defense For (Name of Student)

(Date)

1. The oral examination and thesis defense of the above named degree candidate was held on

(Day of Week),

in Room No. in (Building).

2. The examination and defense began at (Time) and was concluded at (Time).

3. The candidate PASSED FAILED (delete whichever not applicable) the oral examination and thesis defense.

4. Qualifications or clarifying statements considered to be important by the Thesis Director (Optional):

(Signature of Thesis Director)

Copy to: Department Chair 